\title{
Guide on Resource Revenue Transparency
}

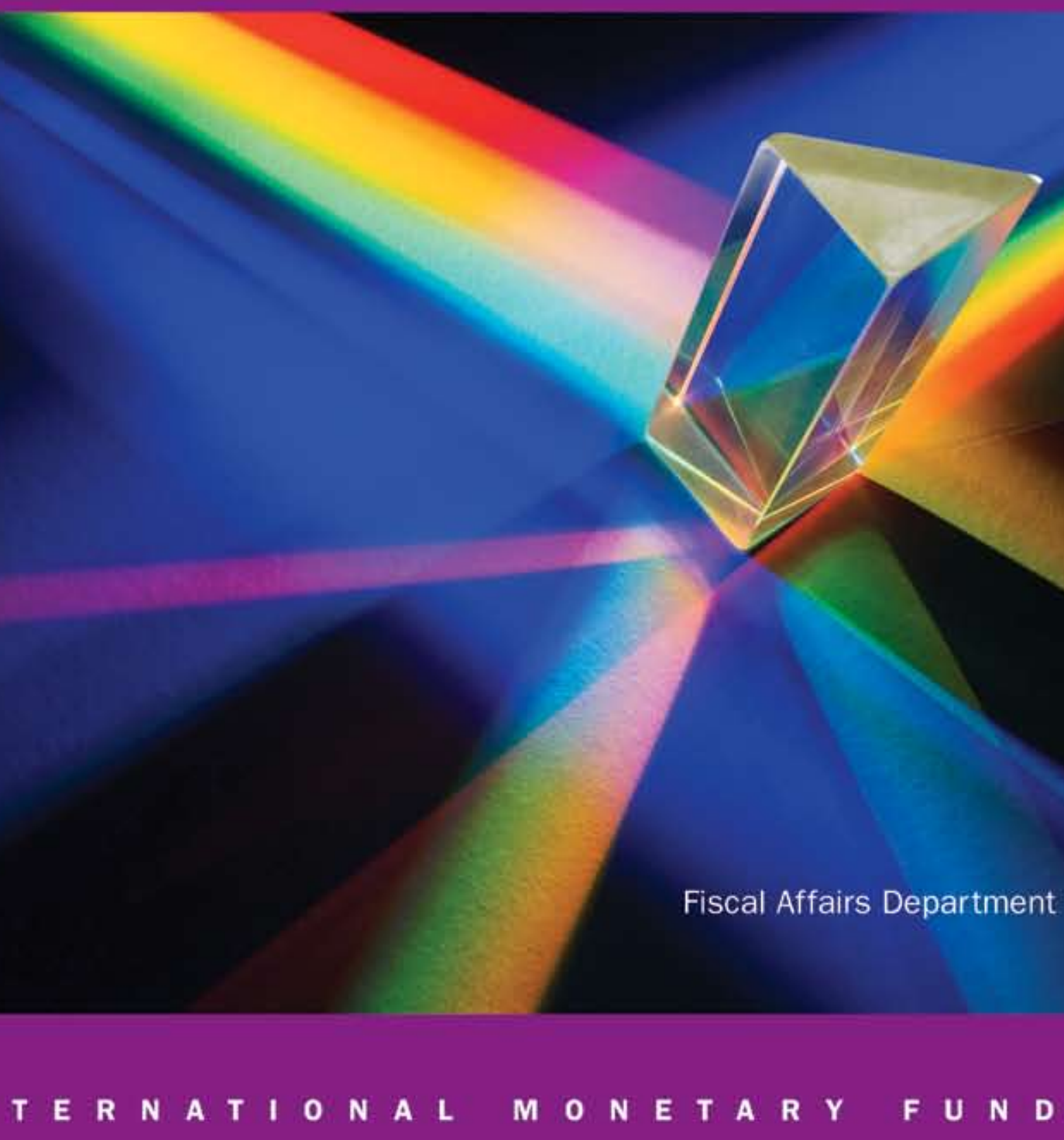

I N TER NATIONAL M O NETARY FUND 


\author{
(C) 2007 International Monetary Fund \\ Production: IMF Multimedia Services Division \\ Typesetting: Alicia Etchebarne-Bourdin
}

\title{
Cataloging-in-Publication Data
}

Guide on resource revenue transparency/Fiscal Affairs Dept., International Monetary Fund-[Washington, D.C.]: International Monetary Fund, 2007.

p. $\mathrm{cm}$.

Includes bibliographical references. ISBN 978-1-58906-463-8

1. Revenue management-Government policy. 2. Transparency in government. 3. Disclosure of information. 4. Petroleum productsEconomic aspects. 5. Gas industry-Economic aspects. 6. Mines and mineral resources-Economic aspects. I. International Monetary Fund. Fiscal Affairs Dept.

HD60.7.G853 2007

Price: US\$15.00

Please send orders to: International Monetary Fund, Publication Services 700 19th Street, N.W., Washington, D.C. 20431, U.S.A.

Tel.: (202) 623-7430 Telefax: (202) 623-7201

E-mail: publications@imf.org

Internet: www.imf.org 


\section{Contents}

Abbreviations and Acronyms $\quad$ v

Preface vii

$\begin{array}{ll}\text { Overview } & 1\end{array}$

Summary of Good Fiscal Transparency Practices for Resource
Revenue Management

I. Clarity of Roles and Responsibilities 11

II. Open Budget Processes $\quad 29$

III. Public Availability of Information 37

IV. Assurances of Integrity 49

Boxes

1. Natural Gas and Fiscal Transparency 15

2. The Fiscal Regime and Government "Take" 17

3. Botswana's Prudent Management of Mineral Wealth 32

4. Norway's Pension Fund-Global: Best Practice Asset
Management

5. Elements of Asset Worth Estimation for Developing Countries 43

6. International Resource Reserves Reporting-Emerging
Standards

Appendixes

I. Hydrocarbon- and Mineral-Rich Countries, 2000-05 (Tables) 54

II. Revised Code of Good Practices on Fiscal Transparency (2007) 57

$\begin{array}{ll}\text { Bibliography } & 61\end{array}$

Website References $\quad 65$ 



\section{Abbreviations and Acronyms}

\begin{tabular}{ll} 
CSO & Civil society organization \\
DMO & Domestic market obligation \\
EITI & Extractive Industries Transparency Initiative \\
G-8 & Group of Eight \\
GDDS & General Data Dissemination System \\
GDP & Gross domestic product \\
GTL & Gas-to-liquid (technology) \\
IFRS & International Financial Reporting Standards \\
IMF & International Monetary Fund \\
IPSAS & International Public Sector Accounting Standard \\
JODI & Joint Oil Data Initiative \\
LNG & Liquefied natural gas \\
MTFF & Medium-term fiscal framework \\
NBIM & Norges Bank Investment Management \\
NDP & National development plan \\
NOC & National oil company \\
NPFG & Norwegian Pension Fund-Global \\
NRC & National resource company \\
OECD & Organization for Economic Cooperation and Development \\
OPEC & Organization of Petroleum Exporting Countries \\
OSI & Open Society Institute \\
OTM & Over-the-counter market \\
PSC & Production sharing contract \\
QFAs & Quasi-fiscal activities \\
ROSC & Report on the Observance of Standards and Codes \\
SDDS & Special Data Dissemination Standard \\
SEC & Securities and Exchange Commission (United States) \\
UNFC & United Nations Framework Classification \\
VAT & Value-added tax \\
& \\
The Code & Code of Good Practices on Fiscal Transparency \\
The Guide & Guide on Resource Revenue Transparency \\
The Manual & Manual on Fiscal Transparency \\
& \\
\hline
\end{tabular}





\section{Preface}

The Guide on Resource Revenue Transparency has become a major reference source since it was first published on the IMF website in 2005. I am delighted that this update is now being distributed in printed as well as electronic form. Its publication coincides with the distribution of the revised Code of Good Practices on Fiscal Transparency (2007) and Manual on Fiscal Transparency.

The Guide supplements the Code and Manual by applying the principles of the revised Code to the specific problems faced by countries rich in natural resources. It provides additional, detailed transparency guidelines, accompanied by explanatory text and examples of good practice in producing countries. A principle objective of the Guide is to help steer resource-rich countries through the special issues arising from the technical complexity and volatility of resource revenue flows and from the sheer magnitude of such transactions. It also provides a framework for assessing resource-specific issues within Reports on the Observance of Standards and Codes (ROSC) fiscal transparency modules.

More generally, the Guide makes available to providers of technical support and civil society a set of authoritative references of good and best practices of resource revenue transparency. For example, the Guide has already been used extensively by the multiple stakeholders of the Extractive Industries Transparency Initiative (EITI). But it also goes beyond the EITI in recommending good practices in the use of resource revenues.

The publication of the Guide underscores the Fund's conviction that transparency is fundamental in establishing and maintaining credibility in the management of resource revenues. The revised Guide contains numerous crossreferences to the revised Manual and has been enhanced by the addition of further examples of good practice and references to recent developments.

I would like to acknowledge past and current staff of the Fiscal Affairs Department responsible both for the initial production and current revision of the Guide, including William Allan, Günther Taube, Charles McPherson, Philip Daniel, Jon Shields, Taryn Parry, Dawn Rehm, Lynn MacFarlane, Ezequiel Cabazon, and Nadia Malikyar. I would also like to thank the many other IMF colleagues who have contributed to the Guide. Martha Bonilla in the External Relations Department edited and coordinated the production of this publication.

\footnotetext{
Teresa Ter-Minassian

Director

Fiscal Affairs Department
} 



\section{Overview}

\section{Background}

1. This Guide on Resource Revenue Transparency (hereafter, the Guide) ${ }^{1}$ applies the principles of the Code of Good Practices on Fiscal Transparency (hereafter, the Code) to the unique set of transparency problems faced by countries that derive a significant share of revenues from natural resources. ${ }^{2}$ It is intended to supplement the Manual on Fiscal Transparency (hereafter, the Manual) by providing a more detailed set of guidelines to address the issues arising from the sheer size of such resources for many countries, combined with the technical complexity and volatility of the transaction flows. The Guide is designed to give a framework for assessing resource-specific issues that may be considered in the fiscal transparency assessments called fiscal transparency modules of Reports on the Observance of Standards and Codes (hereafter, fiscal ROSCs). ${ }^{3}$ But, equally important, the Guide provides a summary overview of generally recognized good or best practices for transparency of resource revenue management that can be used by resource-rich countries or by IMF staff, the World Bank, and other providers of technical support and civil societies.

2. Some have argued that there is an association between resource riches and poor economic performance (the "paradox of plenty" or "resource curse"), and a significant body of literature has sought to explain the relationships between resource abundance and economic performance. ${ }^{4}$ But the resource curse is not inevitable: a range of countries with prudent and transparent management practices (including Botswana, Canada, Chile, and Norway) has benefited from resource wealth. ${ }^{5}$ The key question for a large number of countries is how they can ensure that their abundance in resources remains a blessing. In addition to the possible adverse impact on growth, resource riches have been seen as a major contributor to corruption and social unrest. In a number of countries, oil, diamonds, and other minerals (and timber) have been associated with causing and financing civil war, with its attendant social and economic costs. ${ }^{6}$ Developing countries with limited capacity also face major challenges in dealing with the high risks and complexity of resource sector transactions. ${ }^{7}$ The tables in Appendix I list more than 50 countries designated as rich in hydrocarbon and mineral
${ }^{1}$ This version of the Guide (May 2007) replaces an earlier version posted on the IMF website in June 2005.

${ }^{2}$ Resource revenue is used here to mean revenues derived from natural resource exploitation. Though some of the principles have wider application, the main focus of this Guide is on revenues from hydrocarbon (oil and gas) and mining.

${ }^{3}$ Since starting its work on standards and codes in the late 1990s, the IMF had, by March 2007, prepared fiscal ROSCs for about half of its member countries. Most of these reports have been published. See http://www.imf. $\mathrm{org} / \mathrm{external} / \mathrm{np} / \mathrm{fad} / \mathrm{trans} /$ index.htm ${ }^{4}$ Auty (1997), for instance, examines the relationship between broadly defined resource-rich groups of countries over the period 1960-90. Sachs and Warner (2000) show a robust inverse relationship between growth and resource riches for a sample of 97 countries over the period 1970-89. However, the above-mentioned view has not remained unchallenged. Hausmann and Rigobon (2003), while supporting the generally inverse relationship, point out that oil-rich countries performed well economically in the 1980 s when oil was doing wellcontrary to what would be expected under the "Dutch disease" hypothesis. Lederman and Maloney (2003) raised doubts about the robustness of the Sachs and Warner findings, and subsequently in Lederman and Maloney (2007) argue, on the basis of case studies, that resource wealth combined with appropriate policies and institutions can contribute significantly to long-term growth.

(continues on next page) 
${ }^{5}$ The importance of institutions as an explanatory variable is stressed by Sala-i-Martin and Subramanian (2003), who provide evidence to show (both in a cross-section study and in the case of Nigeria) that the impact of resource wealth is strongly linked to its impairment of institutional quality, and that little of the effect arises from natural resource endowments per se. ${ }^{6}$ See Collier (1999) for a discussion of the costs of civil conflict. Collier and Hoeffler (2004) discuss the substantial net payoff from increased transparency through its impact on conflict prevention. ${ }^{7} \mathrm{McPherson}$ and MacSearraigh (2007) provide an updated review of "resource curse" issues and emphasize the high risks and potential consequences in the petroleum sector.

$8 \mathrm{~A}$ country is considered rich in hydrocarbons and/or mineral resources if it meets either of the following criteria: (1) an average share of hydrocarbon and/or mineral fiscal revenues in total fiscal revenue of at least 25 percent during the period 2000-05 or (2) an average share of hydrocarbon and/or mineral export proceeds in total export proceeds of at least 25 percent during the period 2000-05. ${ }^{9}$ See Katz and others (2004) for an analysis of key issues and a general application of the fiscal transparency code to sub-Saharan African oil-rich countries. Birdsall and Subramanian (2004), although arguing for direct distribution of a portion of oil proceeds to the population in the case of Iraq, also stress the need for a comprehensive policy by the international community to establish transparency and governance standards. ${ }^{10}$ See: http://www.eitransparency. org/section/abouteiti.

(continues on next page) resources. ${ }^{8}$ Many of these are low- and middle-income countries in which resource revenue (principally in petroleum-rich countries) accounts for over 50 percent of government revenue or export proceeds.

3. One explanation for the relatively poor performance of nonresource sectors in some resource-rich economies is that activity is drawn away from the nonresource sector by the impact of a rising value of resource exports on the exchange rate and competitiveness (sometimes known as "Dutch disease"). Careful macroeconomic management and prudent fiscal policy can mitigate the impact of this phenomenon, and a transparent approach to fiscal policy will provide a sound basis for securing public support for the difficult policy and spending choices that are sometimes required over the longer term. More fundamentally, however, many analysts have emphasized the essential role played by fiscal transparency in improving resource revenue management, which will foster the efficient use of public funds, reduce the risk of unstable macroeconomic policies, and improve confidence in the budget process. ${ }^{9}$

4. Given the potentially substantial costs of nontransparent practices, institutional strengthening to improve transparency in vulnerable resource-rich countries should provide an ample pay off for a relatively modest investment. In particular, transparency can help establish and maintain credibility in regard to the collection and distribution of resource revenue. This was one of the motivations behind the creation in 2002 of the Extractive Industries Transparency Initiative (EITI). ${ }^{10}$ In the past several years, moreover, considerable agreement has been reached on a wide variety of good resource revenue management practices (particularly oil and gas). ${ }^{11}$ This Guide draws heavily upon this body of work in seeking to integrate transparency-related recommendations within the framework of the Code.

5. The Guide focuses on actual and potential revenues from nonrenewable resources, and especially on oil and gas. Oil production provides the most dramatic illustration of the problems posed by resource riches for developing countries: very large, quickly growing, but time-limited production and revenue flows, combined with a high degree of volatility because of fluctuating world prices. When administration is weak, ownership of such wealth provides ample scope for inefficient policies, discretionary behavior, and outright corruption, all of which could contribute to poor growth performance and eventual dissipation of national oil wealth. ${ }^{12}$

6. Similar concerns, albeit usually on a lesser scale, can arise in managing other nonrenewable resources (e.g., copper, diamonds, and gold). Most of the practices suggested in the Guide therefore apply with similar force to other extractive industries. Specific problems differ for each type of industry, and even within the hydrocarbon sector, issues faced in natural gas development differ significantly from those of the oil industry. Various mining industry sectors also face some unique problems. The Guide focuses on the common need among these sectors to manage resource asset wealth and revenues in a transparent way, but it also notes some of the distinctive industry-specific concerns across the variety of extractive industries. 
7. Some of the practices suggested in this Guide for the petroleum and mining industries are applicable at a very general level to renewable resource assets, such as forestry and fisheries, particularly with regard to openness of the legal framework and fiscal regime, clear documentation of resource revenues, and effective accounting and audit of revenue flows. However, with one or two important exceptions, the magnitude of resource revenue flows to governments in these industries generally does not pose the level of potential problem posed by large hydrocarbon resources. The primary concerns for these industries are managing a common pool resource, taking effective account of the environmental impact, and establishing prudential rules. Industry-specific transparency concerns of forestry and fisheries are beyond the scope of this Guide.

\section{Revisions to the Code, Manual, and Guide}

8. This Guide has been updated from the first edition (2005), mainly to align it with the revisions made to the Code and Manual in May 2007. These revisions include a change in the ordering of the four pillars of fiscal transparency (and hence in the ordering of the chapters in the Manual and Guide) and changes to some of the good practices on fiscal transparency. (The revised Code is shown in Appendix II.) Revisions to the Code of particular relevance to resource revenue transparency include the addition of the following good practices:

- Contractual arrangements between government and public or private entities, including resource companies and concession operators, should be clear and publicly accessible. (1.2.4)

- Government liability and asset management, including the granting of rights to use or exploit public assets, should have an explicit legal basis. $(1.2 .5)$

- Receipts from all major revenue sources, including resource-related activities and foreign assistance, should be separately identified in the annual budget presentation. (3.1.4)

- The government should publish a periodic report on long-term public finances. (3.1.7)

- Purchases and sale of public assets should be undertaken in an open manner, and major transactions should be separately identified. (4.2.4)

9. Other revisions to the Code include the broadening of some practices to make more explicit requirements, such as the specification of a medium-term fiscal policy framework and an audit of the final accounts. The updated Manual also deals more deeply with some matters relevant for resource revenue transparency, including public-private partnerships, concessions, and guarantees.

10. In addition to its alignment with the strengthened practices in the Code, the Guide has been enhanced in a few areas, including the discussions on medium-term frameworks, long-term reports, resource-related funds, and internal oversight of revenue flows. It has also been updated in line with some
${ }^{11}$ Key analytical studies are Davis and others (2003) and World Bank, Petroleum Revenue Management Workshop proceedings (2004). IMF operational work includes technical assistance for Timor-Leste, a conference on fiscal policy in oil-producing countries held in Washington in June 2002, and the workshops on macroeconomic policies and governance in African oil-exporting countries that took place in Douala on April 2003 and in Libreville in January 2004.

${ }^{12}$ In Transparency International's Corruption Perception Index, a number of oil-rich countries have rather low scores. For the results of the 2006 survey see http:// www.transparency.org/cpi/. 
${ }^{13}$ See, for example, Gabon Fiscal ROSC, 2006, and Indonesia Fiscal ROSC, 2006. Resource-rich countries for which fiscal ROSCs have been published are highlighted in Tables 1 and 2 of Appendix I. They include both oil producers (e.g., Algeria, Azerbaijan, Equatorial Guinea, Islamic Republic of Iran, Kazakhstan, Mexico, and Russia) and mineral producers (e.g., Chile, Ghana, Kyrgyz Republic, Mauritania, Mongolia, Papua New Guinea, Peru, and Zambia) assessed before compilation of the Guide.

${ }^{14}$ See http://www.imf.org/ external/standards/index.htm.

${ }^{15}$ In its report, "Implementation of the Management Response to Extractive Industries Review," December 2006, the World Bank Group emphasized, among other things, its continuing strong support of the EITI. See http:// siteresources.worldbank.org/ INTOGMC/Resources/ implementationtomr2.pdf. ${ }^{16}$ Civil society organizations (CSOs) represented on the board include Global Witness, the Open Society Institute (OSI), and Transparency International UK. The launch of the EITI was strongly supported by a coalition of some $300 \mathrm{CSOs}$, which launched a campaign in 2002 called Publish What You Pay (PWYP), seeking to oblige marketquoted international oil and gas companies to publish their payments to individual governments on a company-by-company basis. An overview of civil society work in monitoring budget use of oil revenue is given in OSI Revenue Watch's Follow the Money: A Guide to Monitoring Budgets and Oil and Gas Revenues. http://www.soros. org/initiatives/cep/articles_ publications/publications/money_ 20041117/follow_money.pdf.

(continues on next page) recent developments, including the new governance structure for the EITI, and has been reinforced by the addition of further country examples.

\section{Recent Work by the IMF, the World Bank, and Other Agencies}

11. One of the main priorities for the fiscal ROSC program is to ensure effective coverage of resource-rich countries. These ROSCs are increasingly being informed by material in the Guide. ${ }^{13}$ Additionally, in other core activities, the IMF has intensified its interaction with resource-rich countries through policy advice, surveillance, workshops, and technical assistance. The IMF has assisted in particular with volatility in commodity prices and the associated macroeconomic and fiscal policy challenges. Studies by IMF staff have highlighted critical aspects of fiscal regimes for ensuring transparency of resource revenues. The IMF also encourages countries to participate in its Special Data Dissemination Standard or General Data Dissemination System (SDDS and GDDS), which call for, for example, the public dissemination of monthly or quarterly oil production data. ${ }^{14}$

12. In its mining and petroleum sector and country work, the World Bank is actively promoting more effective resource management practices by both national companies and governments. Following a review of its lending and support activities in oil, gas, and mining production, the Bank has placed considerable emphasis on revenue transparency as a basis for its continuing involvement in such projects. ${ }^{15}$ IMF and World Bank teams have worked very closely together on a number of projects in resource-rich countries, such as Azerbaijan and Nigeria.

13. Following its conference in Oslo in 2006, the EITI, which focuses on the transparency of revenue payments and receipts in resource-rich economies, acquired the status of an international organization. A multi-stakeholder board was established, with 19 members representing five constituencies: implementing countries, supporting countries, civil society organizations, company or company associations, and institutional investors. ${ }^{16}$ The chair of the board is independent. A small secretariat is being constituted in Oslo in 2007. The IMF and World Bank attend board meetings as observers and provide technical advice and support to the EITI. ${ }^{17}$ Together with other broader transparency and anti-corruption initiatives, both fiscal ROSCs and the EITI process have been strongly supported by the Group of Eight (G-8) countries at successive G-8 summits. ${ }^{18}$

14. Improvements in the quality and dissemination of oil market data have been fostered at a global level by the Joint Oil Data Initiative (JODI). ${ }^{19}$

\section{Approach and Structure of the Guide}

15. The structure of the Guide follows that of the Manual. It contains four chapters, each corresponding to one of the four pillars of fiscal transparency: (1) clarity of roles and responsibilities, (2) open budget processes, 
(3) public availability of information, and (4) assurances of integrity. Within each chapter, the Guide lists a series of resource-specific good practices of fiscal transparency and cross-references these to specific good practices in the Code (identified by three-digit references). As in the Manual, a few practices draw on standards that are complementary to the Code (e.g., international accounting and auditing standards). ${ }^{20}$ The Guide also gives illustrations of practices in specific countries and addresses issues that have arisen in their implementation, drawn from recent literature on these topics or directly from country experience. (In many cases, the text includes website references to provide direct access to more detailed information.)

16. The Guide is designed to be used in a similar way to the Manual by providing supplementary material on resource-related practices. Implementation of the good practices discussed in the Guide is voluntary. For resource-rich countries, as for others, participation in a fiscal ROSC is an important step in identifying areas of transparency weakness and strength, as well as signaling a commitment to reform. While serving as a reference source on good practices for country authorities, the Guide provides a basis for discussions with IMF staff and other external agencies, which might include the potential provision of technical assistance or other activities designed to improve resource revenue transparency and management.

17. In promoting resource revenue transparency, it is particularly important to recognize the diversity of country backgrounds. The pace of reform must suit individual country circumstances. The Guide recommends practices drawn from the experience of advanced economies, as well as some emerging market and developing countries that are improving their transparency standards. These provide appropriate points of reference. However, many developing countries have to overcome underlying capacity constraints before they can fully align themselves with these practices. The Guide, therefore, seeks to avoid setting the bar too high; it allows countries to assess where they stand relative to recognized good practice. Addressing weaknesses will require time, sustained commitment, and close linkages among fiscal transparency assessments, country administrative reform, and carefully designed technical support from international and bilateral agencies.

18. Countries will need to establish priorities among the suggested practices both over time and according to their specific circumstances. A high immediate priority should be given to improving the quality and public disclosure of data on resource revenue transactions, using either mechanisms required under the EITI or alternative formats that provide adequate assurance of data quality. Transparency of current revenue transactions is an area in which many low- and middle-income countries can make immediate measurable progress, with technical support if necessary. Equally high priority should be given to establishing clear policies regarding the pace of extraction and the use of resource revenues. The need to preserve the value of the finite resource assets, and the wise use of proceeds from selling these assets, should be clearly recognized in fiscal policy frameworks. Other issues present more difficulties, and progress will necessarily be slower. For instance, there are high degrees of uncertainty over the value of resource assets owned by govern-
${ }^{17}$ Other international organizations, including the African Development Bank, European Bank for Reconstruction and Development, and the Organization for Economic Cooperation and Development (OECD), are also involved in board activities and support the EITI process.

18The 2003 Evian G-8 Declaration: Fighting Corruption and Improving Transparency encouraged participation and publication of fiscal transparency ROSCs as an important tool. This position has been reiterated at subsequent G-8 summits, most recently at St. Petersburg (http://en.g8russia. $\mathrm{ru} /$ docs/14.html). At the 2004 Sea Island Summit, four countries (Georgia, Nicaragua, Nigeria, and

Peru) came forward with compacts declaring their intention to implement fiscal transparency goals. The Gleneagles Summit (2005) endorsed the EITI. ${ }^{19}$ See http://www.jodidata.org/ FileZ/ODTmain.htm.

${ }^{20}$ The Manual, for instance, draws on the OECD Principles of Corporate Governance with regard to public enterprise reporting, which is of particular relevance to treatment of national resource companies; the UN Code of Conduct for Public Officials; and the UN Fundamental Principles of Official Statistics. 
ments, and methodological and measurement problems complicate the estimation of resource asset worth. Progress in implementing the recommended transparency practices on resource asset estimates and their integration into government balance sheets and net worth calculations will thus be limited over the short term, especially in low- and middle-income countries.

19. The remainder of the Guide is organized as follows. First, a summary is provided of good fiscal transparency practices for resource revenue management. The following four chapters then discuss these practices and related issues in more detail. Chapter I deals with applying the Code precept of clarity of government roles and responsibilities to resource revenues. Chapter II discusses issues related to open budget processes, with an emphasis on the need to link resource revenues clearly to overall goals of fiscal stabilization and longterm sustainability. Chapter III focuses on public availability of information, including the application of EITI guidelines. Chapter IV focuses on the issues of establishing overall assurances of integrity in resource revenue management. Appendix I lists countries that are defined as resource rich in either (or both) hydrocarbons or minerals. Appendix II contains the revised Code. 


\section{Summary of Good Fiscal Transparency Practices for Resource Revenue Management}

An overview of the good practices of resource revenue transparency suggested in the Guide as the basis for voluntary compliance is presented below. The practices are listed using the same broad structure as the Code, which groups fiscal transparency good practices according to four pillars. ${ }^{21}$ The three-digit references alongside each resource-specific good practice identify the related good practices in the revised Code (2007).

\section{Clarity of Roles and Responsibilities}

\section{A. Legal Framework for Resource Revenues}

$1.2 .4 / 1.2 .5$

The government's ownership of resources in the ground should be clearly established in law, and the power to grant rights to explore, produce, and sell these resources should be well established in laws, regulations, and procedures that cover all stages of resource development.

\section{B. Fiscal Regime}

$1.2 .2 / 1.2 .4$

The government's policy framework and legal basis for taxation or production-sharing agreements with resource companies should be presented to the public clearly and comprehensively.

\section{Authority over Revenue Flows and Borrowing}

Fiscal authority over resource-related revenue and borrowing is clearly specified in the law. Legislation should require full disclosure of all resourcerelated revenue, loan receipts and liabilities, and asset holdings.

\section{Equity Participation}

Government involvement in the resource sector through equity participation should be fully disclosed and the implications explained to the public.

\section{E. National Resource Companies}

Ownership structures of national resource companies and their fiscal role vis-à-vis the resource sector ministry and the finance ministry should be clearly defined.
${ }^{21}$ The good practices described in the Guide are those that country experience suggests are essential elements of resource revenue transparency and that all countries should take into account in designing fiscal management and reporting systems. For expositional purposes, the elements of good practice are presented to highlight key resource industry issues rather than following the Code sequence in strict order. 
Commercial responsibilities should be clearly distinguished from policy, regulatory, and social obligations.

\section{F. Quasi-Fiscal Activities of Resource Companies}

Arrangements whereby international or national resource companies undertake social or environmental expenditure or provide subsidies to producers or consumers without explicit budget support should be clearly defined and described in the budget documentation.

\section{G. Subnational Government and Resource Revenues}

Arrangements to assign or share resource revenues between central and subnational levels of government should be well defined and explicitly reflect national fiscal policy and macroeconomic objectives.

\section{Open Budget Processes}

\section{A. Fiscal Policy and Resource Revenues}

2.1.2/2.1.4

The budget framework should incorporate a clear policy statement on the rate of exploitation of natural resources and the management of resource revenues, referring to the government's overall fiscal and economic objectives, including long-term fiscal sustainability.

\section{B. Fiscal Policy, Resource-Related Funds, and the Budget}

Mechanisms for coordinating the operations of any funds established for resource revenue management with other fiscal activities should be clearly specified.

\section{Operations of Resource-Related Funds}

Operational rules applied to resource-related funds should be clearly stated as part of an overall fiscal policy framework.

\section{Fiscal Policy and Asset Management}

The investment policies for assets accumulated through resource revenue savings should be clearly stated, including through a statement in the annual budget documents.

\section{E. Accounting for Resource Revenues}

The government accounting system or special fund arrangements should clearly identify all government resource revenue receipts and enable issuance of timely, comprehensive, and regular reports to the public, ideally as part of a comprehensive budget execution report. The reports should be based on a clear statement of the accounting basis (cash or accrual) and policies. 


\section{Public Availability of Information}

\section{A. Budget Documentation of Resource Revenues and Spending}

All resource revenue-related transactions, including through resource funds, should be clearly identified, described, and reported in the budget process and final accounts documents.

\section{B. Reporting on Company Resource Revenue Payments}

Reports on government receipts of company resource revenue payments should be made publicly available as part of the government budget and accounting process.

\section{Fiscal Balance}

The (primary) nonresource fiscal balance should be presented in budget documents as an indicator of the macroeconomic impact and sustainability of fiscal policy, in addition to the overall balance and other relevant fiscal indicators.

\section{Reporting on Resource-Related Debt}

The government's published debt reports should identify any direct or indirect collateralization of future resource production, for instance through precommitment of production to lenders. All government contractual risks and obligations arising from such debt should be disclosed.

\section{E. Reporting on Assets}

All financial assets held by government domestically or abroad, including those arising from resource-related activities, should be fully disclosed in government financial statements.

\section{F. Estimating Resource Asset Worth}

Estimates of resource asset worth based on probable production streams and assumptions should be disclosed.

\section{G. Reporting Contingent Liabilities and Quasi-Fiscal Activities}

Government contingent liabilities and the cost of resource company quasifiscal activities arising from resource-related contracts should be reported in budget accounts or other relevant documents in a format that helps assess fiscal risks and the full extent of fiscal activity.

\section{H. Fiscal Risks}

Risks associated with resource revenue, particularly price risks and contingent liabilities, should be explicitly considered in annual budget documents, 
and measures taken to address them should be explained and their performance monitored.

\section{Assurances of Integrity}

\section{A. Internal Control and Audit of Resource Revenues}

Internal control and audit procedures for handling resource revenue receipts through government accounts or special fund arrangements, and any spending of such receipts through special funds, should be clearly described and disclosed to the public.

\section{B. Tax Administration Openness}

Tax administration should be conducted to ensure that resource companies understand their obligations, entitlements, and rights. The scope for discretionary action by tax officials should be clearly defined in laws and regulations, and the adequacy of sector skills and standard or sector-specific procedures should be open to review.

\section{Oversight of Companies}

4.3.1/1.1.5

International and national resource companies should comply fully with internationally accepted standards for accounting, auditing, and publication of accounts.

\section{Oversight of Company/Government Revenue Flows}

A national audit office or other independent organization should report regularly to the legislature on the revenue flows between international and national companies and the government and on any discrepancies between different sets of data on these flows. 


\section{Clarity of Roles and Responsibilities}

20. Much of resource revenue management hinges on the relationships between the government, national resource companies (NRCs), and international companies. These relationships must be clearly defined for all stages of resource development. Extractive industries can affect the economy or environment at any stage from exploration through to abandonment. Exploration is usually the highest-risk element of any extractive industry project, though there is a difference in this respect between mining and petroleum, ${ }^{22}$ and substantial expenditure is generally required before a discovery is confirmed. Any government policies intended to encourage investment by international companies or using NRCs at various stages of development should be clear. In the petroleum industry, particular emphasis needs to be placed on clarifying the role of the national oil companies (NOCs). These still produce much of the world's oil and often play a strong policy role relative to the rest of government. This chapter of the Guide examines the legal framework governing these relationships, the special nature of the fiscal regime for resource companies, the broad role of NRCs, including their noncommercial activities, and the clarity of revenue sharing arrangements with lower levels of government.

\section{A. Legal Framework for Resource Revenues 1.2.4/1.2.5}

The government's ownership of resources in the ground should be clearly established in law and the power to grant rights to explore, produce, and sell these resources should be well established in laws, regulations, and procedures that cover all stages of resource development.

\section{The basic legal framework}

21. Legal title to the nation's resources in the ground is established through the constitution and national laws, as well as subnational laws in some cases. The power to grant rights to explore, produce, and sell these resources should also be clearly established in laws, regulations, and procedures covering all
${ }^{22}$ It is more common for mining projects to fail at the development and production stage (something that is highly unusual in petroleum); the ratio of exploration to development outlays tends to be lower in mining. 
${ }^{23}$ In Yemen, individual productionsharing contracts become law by virtue of a presidential decree. stages of resource development. The legal framework needs to establish a basis for reconciling the divergent interests of key stakeholder groups, including the state, private investors, owners of surface land rights, parties that can be affected by the social and environmental impact of extractive industries, and civil society. In terms of fiscal transparency, particular emphasis needs to be given to the clarity of the framework for relationships between the government and (private) investors, because many transactions arising from these relationships have fiscal implications. Also, transparency of the legal framework provides an important safeguard for foreign investors and should help ensure effective use of the resources for public benefit. An increasingly important part of the legal framework is the establishment of laws and regulations that give assurance that revenues and accumulated assets are managed transparently through the budget process to achieve national objectives.

22. The constitutional foundation is an important factor, but constitutions differ significantly in the degree to which they

- recognize or guarantee private property rights or prohibit private parties or foreigners from acquiring property rights in general and mineral rights in particular;

- vest the authority to grant mineral or hydrocarbon rights in subnational governments or agencies rather than the national government; and

- vest the authority to regulate specific matters in special agencies in the executive branch (for example, taxation, foreign exchange, employment, or environmental protection) or in the judiciary (settlement of disputes).

23. The legal framework should define which political entity and official has the authority to grant mineral or hydrocarbon rights and regulate their use. In most countries, the sovereign state is the owner of the resource and can grant rights to private parties. Often, this authority is exercised through a sector ministry, which is likely to have power over the application of relevant laws and policies, and the implementation of the government's decisions on the pace of, say, petroleum sector development, by making available areas for exploration and granting licenses. In some countries (such as Azerbaijan and Egypt), licenses are ratified by the legislative branch of the government, ${ }^{23}$ although this does not necessarily mean the contracts, or summaries thereof, are disseminated to the public. Given the typically significant macroeconomic impact of hydrocarbons in particular, national policymakers normally prefer to retain authority at the national level (see discussion of subnational government authority below).

24. Modern legal frameworks for resource industries tend to emphasize an environment that is open to domestic and foreign investors, while establishing clear state authority over all stages of development from access to blocks for exploration to production and site abandonment. Two central features of the framework in terms of transparency are (i) avoidance of excessive complexity and opportunities for official discretion in implementation and (ii) encouragement of disclosure of all fiscal and quasi-fiscal arrangements. Best practices for such 
legislation in this respect are (i) standard agreements and terms for exploration, development, and production, with minimum discretion for officials, though these terms may vary over time; (ii) clear and open licensing procedures; (iii) disputes open to (international) arbitration; and (iv) disclosure of individual agreements and contracts regarding production from a license or contract area. These practices are relatively standard in the advanced economies and are increasingly an area of focus for resource-rich developing and emerging market economies. Application of these principles of transparency will be examined further, first with respect to licensing procedures and then in relation to the fiscal regime.

\section{Licensing procedures}

25. Clarity and openness of licensing procedures are fundamental to achieving transparency during subsequent stages of development. Taking the petroleum industry as an example, licensing practices vary in both the complexity of terms and disclosure practices. ${ }^{24}$ They can be grouped in three broad categories in line with these criteria:

\section{Open bid-fixed terms}

26. Open tendering with clearly defined procedures and sealed bids constitutes best practice. A sealed bid license round with fixed terms is used in the United Kingdom, New Zealand, Ireland, Norway, and Australia. The royalties and taxes are not biddable, but set by law. Licenses are awarded on the basis of work program (or sometimes expenditure) bids. ${ }^{25}$ Timor-Leste, a new petroleum- and gas-producing country, has aimed at establishing internationally competitive open-bid processes at the outset (based on the offered work program). Bids received and final contract awards are disclosed publicly. ${ }^{26}$ Ultimately the seismic data and drilling data from the successful bidder will also become public. ${ }^{27}$ The United States uses open bidding for offshore projects, with relatively fixed terms, and publishes the bids and license awards, but it allocates licenses on the basis of signature bonus bidding (that is, a variable term, as discussed below).

\section{Open bid-variable terms}

27. Some countries have significant variation in their terms. Licenses may be allocated in a sealed bid process based upon various bid parameters that might include work programs, bonuses, royalty rates, profit oil splits, cost recovery limits, and possibly even tax rates. As a general rule, corporate income tax is legislated and not a bid item. Disclosure of winning bids and contracts is an important element of transparency, although interpretation becomes increasingly complex with the number of bid parameters. Bidding rounds should be open to scrutiny by international observers.

\section{Negotiated deals}

28. Negotiated deals are characterized by the lack of sealed bids and firm bid deadline, and, most often, considerable discretion on the part of the

\footnotetext{
${ }^{24}$ However, in mining, rights are often subject to a "first come, first served" principle that almost never applies to petroleum licensing.

${ }^{25}$ In work program bids, companies interested in a particular block will submit a proposal that is typically denominated in terms of the number of wells it will drill and/or the quantity of seismic data it will acquire. Furthermore, the depth of the wells and the nature of the seismic data to be acquired, processed, and interpreted will be included. There is a case to be made, particularly in mining, for allocating areas by minimum expenditure bid, because the nature of a required work program may be more uncertain for a mineral deposit. ${ }^{26}$ Recent improvements in the bidding processes in Timor-Leste as well as in Angola and Nigeria are summarized in McPherson and MacSearraigh (2007).

${ }^{27}$ Data acquired by an operator within the scope of its license are made public either when the exploration, development, or production contract terminates or after a certain number of years (8 years in Australia, 35 years for U.S. operations in the Gulf of Mexico). Multiclient data (acquired by a service company on a risk basis to assist the government in promoting its prospects) are normally marketed by the service company for about 8-10 years, after which they become public.
} 
government agent (e.g., the Ministry of Energy or the NOC). Disclosure of winning bids is also not generally part of the process. Though some terms may be fixed, generally a wide range are subject to negotiation. Companies will make proposals to the government authority, which will ultimately award the licenses to those companies submitting the most competitive proposals. This approach can be fairly efficient but carries a greater risk of corruption. Good practice as far as disclosure is concerned would at least include ex post publication of contract awards and terms. Egypt provides an example of good practice in this respect: all contracts are made public, although licenses may be awarded through either negotiated deals or bid rounds.

29. In the current petroleum industry environment, many situations do not lend themselves to open tendering and competitive bidding. Most of the world's geological basins have matured to the point that significant new discovery expectations are much lower than in earlier eras. International companies, particularly smaller ones, are not in a position to invest in exploration or release ideas about prospects to either licensing authorities or competitors. An ordinary tender for bids in the early stages of exploration of frontier or gas-prone regions (see discussion of natural gas in Box 1), for instance, is thus likely to fail because of the high risks and up-front costs. Negotiated deals are thus common in these situations. Good practice for transparency, however, would require publication of all signed contracts.

30. An often expressed concern with regard to open tendering processes is that both government and companies may lose their competitive advantage by public disclosure of winning contracts. For reasons of commercial confidentiality, therefore, negotiated contracts with nondisclosure clauses are the practice in a number of countries. The reason usually advanced by governments (and to some extent by companies) is that disclosure would erode their bargaining power for future contracts. In practice, however, the contract terms are likely to be widely known within the industry soon after signing. Little by way of strategic advantage thus seems to be lost through publication of contracts. Indeed, it could be argued that the obligation to publish contracts should in fact strengthen the hand of the government in negotiations, because the obligation to disclose the outcome to the legislature and the general public increases pressure on the government to negotiate a good deal.

\section{B. Fiscal Regime}

1.2.2/1.2.4

The government's policy framework and legal basis for taxation or production sharing agreements with resource companies should be presented to the public clearly and comprehensively.

31. The high risks, high returns, and prolonged development of extractive industries mean that the fiscal regime for these sectors has many unique features, is generally complex, and, as indicated above, often has significant scope for discretionary arrangements in individual agreements. Ideally, a government will wish to establish a regime that both is attractive to potential investors and gains a fair share of resource rent. The fiscal regime should be 


\section{Box 1. Natural Gas and Fiscal Transparency'}

Natural gas has become an increasingly important global energy source. It is attractive from an environmental point of view, demand is foreseen to grow rapidly, and supply has seemed adequate to meet demand for several decades. Nonetheless, its development faces some unique difficulties, quite distinct from crude oil projects, largely because of its heavy dependence on a costly transport infrastructure and the absence of a broad-based market price. Aside from the economic consequences of the nature of gas supply, these features pose particular difficulties for the establishment of a transparent fiscal regime.

Natural gas, which may or may not be associated with crude oil in a reservoir, is transported by pipeline or, as liquefied natural gas (LNG), by tanker. The application of gas-to-liquid (GTL) technology is increasingly seen as a viable alternative to LNG for processing of remote gas. LNG contracts raise different considerations than do pipeline gas contracts, which often involve multilateral negotiations over transit rights. Moreover, the LNG contract chain (production and liquification, transportation, and receiving terminal) can be broken down into independent segments, allowing financing to proceed in stages. In the context of developed market economies in North America and Europe, deregulation aimed at encouraging competition in each segment of the gas contract chain, combined with increased trade of gas, appears to have been relatively successful, resulting in generally lower but also more volatile gas prices.

Much of the world's natural gas reserves are considered "stranded" because remote locations, high transportation costs, and often high political risks make their exploitation commercially not viable. However, prospects of commercial exploitation of these "stranded" resources improve if gas prices rise and technological progress progressively lowers the costs of LNG and GTL plants.

Location, the lumpiness of investments, and the interdependence of segments of the contract chain (for instance, except for the very largest companies, a production contract cannot be securely completed until the tanker transportation has been arranged) have tended to lead to an environment favoring negotiated deals rather than open bidding for contracts.

Where domestic consumption is an important element of natural gas projects, gas consumer prices should be based at least on full cost recovery-and preferably linked to international prices. Otherwise, quasi-fiscal subsidies of domestic use of natural gas will understate government activity, distort energy demand, and limit the attractiveness of the resource to private sector investors.

${ }^{1}$ Based largely on Okogu (2002). clearly and comprehensively set out in government policy statements and incorporated in the resource and tax laws.

32. In the petroleum industry, apart from the substantial amount of production under direct state ownership, ${ }^{28}$ there are two broad types of fiscal systems used to determine shares of resource rent between the government and investors: (i) tax/royalty systems, in which companies are licensed to explore, exploit, and sell the oil and are subject to a range of tax (as well as non-tax) instruments; and (ii) production-sharing contract (PSC)
${ }^{28}$ Out of a total production of about 81 million barrels per day in 2005 , some 25 million were produced by Middle Eastern OPEC countries (e.g., The Islamic Republic of Iran, Kuwait, and Saudi Arabia) under partial or total state ownership. See BP (2006) and Daniel (2002a). 
${ }^{29}$ Resources in the ground are usually the property of the state, except in a few countries (e.g., the United States) where private ownership of minerals in the ground is legal. Title to petroleum usually passes to the licensee or contractor at the "delivery point;" under a license in a tax/ royalty system the licensee will obtain title to all the petroleum at that point, whereas under a PSC the contractor obtains title to the contractor's share.

${ }^{30}$ The use of PSCs is not common in hard rock mining; see Kumar (1995, p. 12).

${ }^{31}$ See Johnston (2004) and Sunley, Baunsgaard, and Simard (2003) for more details on the instruments used under each type of regime. The latter indicate that two-thirds of the 40 developing countries and emerging markets surveyed applied PSCs, generally combined with some form of royalty or income tax.

${ }^{32}$ For a summary discussion of petroleum tax regimes see Daniel (2002b).

${ }^{33}$ Norway provides an example of best practice in this respect. The Ministry of Petroleum provides regular electronic publications including regularly updated fact sheets on the Norwegian petroleum sector covering the regulatory and fiscal framework (see http://www.regjeringen.no/en/ ministries/oed.html?id=750). The tax/royalty regime builds on the normal corporation tax (in 2003, 28 percent) and adds a special tax of 50 percent. The policy on depreciation and the deductions allowed in calculating ordinary and special taxes are clearly specified. In addition, companies pay royalties on production (but this is being phased out), area fees, and carbon tax. The government also receives dividend income from equity holdings (in most petroleum fields and transport systems on the continental shelf). arrangements, whereby companies are contracted to extract and develop the resource in return for a share of the production. ${ }^{29}$ A number of other fiscal arrangements may apply to either regime. The PSCs may also embody some tax or royalty elements. ${ }^{30}$ And even under a PSC system, it is common for the contractor to pay corporate income tax under general tax legislation, either directly, or indirectly through a mechanism involving the state partner (usually the NOC). This practice has evolved largely in response to companies' desire to receive foreign tax credits in their home jurisdictions. Either system can be designed to achieve identical ends with regard to revenue shares and risk-reward mix, and a fiscal regime may incorporate aspects of both systems. Although the greatest part of world oil production does not occur under PSCs, these have become the main system of choice for many developing countries, particularly those opening up new areas or remodeling their arrangements. ${ }^{31}$

\section{Tax or royalty systems}

33. Industrialized countries have tended to rely more on tax or royalty systems. As a rule, these countries build on the basic corporation tax regime and so have a solid basis in general taxation law. Each type of system, however, poses transparency challenges, and the nature of the investment makes resource taxation complex. The main elements of tax or royalty regimes are described below. Practical approaches to assessing government or industry "take," which aim at providing a summary indicator encompassing many aspects of the fiscal regime in the petroleum industry, are described in Box 2.

34. The normal range of tax instruments can be applied to resource industries-and it is vital that the definition of the industry fiscal regime cover all instruments actually applied. Profitability and risk considerations will likely lead to special rates and an industry-specific, multi-instrument regime designed to meet the needs of government and the industry. In principle, the policies underlying such a regime should be stated openly to the public and the tax treatment of the industry should be subject to normal budgetary and public scrutiny. In practice, regimes cover a wide spectrum. At one end, as envisaged by Cordes (1995), resource companies are subject to the same regime as other industries except for some form of additional profits tax (such as a "resource rent tax") geared to high profitability and some form of royalty equivalent to ensure a minimum revenue flow. At the other extreme, various instruments and rates may be used in a case-by-case approach that attempts to optimize government returns relative to risks. The more complex and discretionary the system, the more difficult it will be to define the basic fiscal regime and achieve better transparency. ${ }^{32}$

35. At the best practice end of the spectrum, it should be possible to define the resource industry tax baseline regime as those normal taxes applied to all corporations, plus a few policy variations (royalties, additional profit tax) that form an integral part of the regime. ${ }^{33}$ Any special concessions beyond these should be identified and reported as tax expen- 


\section{Box 2. The Fiscal Regime and Government "Take"}

Because of the complexity of country-specific fiscal regimes, a common approach to analyzing production sharing contracts and other arrangements is to prepare a summary estimate of the projected overall division of rents between company and government resulting from all instruments. This is often referred to as the government "take" (see Johnston, 2004; and Kumar, 1995). Effectively, the estimation collapses all of the rent extraction mechanisms into the equivalent of a single cashflow-based tax taken over the life of the project.

Particularly for frontier regions following an initial discovery, very little information is generally available, and both government and company negotiators will necessarily build a variety of risk assumptions into the projections. After a contract is signed, however, provided that risks are clearly stated, an overall summary of the projections and relative take could be an important element of disclosure. Indeed, without a summary overview, disclosure of contract terms is likely to be quite difficult to interpret. Data on government take across countries and projects are relatively readily available in the industry, but their potential significance for transparency has been underemphasized.

A summary at this level does, however, have obvious limitations, as stressed by Johnston (2004). Among other things, a single statistic cannot capture the differing share of risks that may emerge from any particular fiscal regime, and coverage may not be comprehensive (e.g., quasi-fiscal activities such as the provision of social services through resource companies are often not included). Moreover, such data do not take account of differences in the structure of the fiscal regime (such as the presence or absence of ring-fencing) and the availability of home country tax credits to foreign investors.

Better standardization of methodology would seem necessary to improve transparency. In this regard, the following should be considered:

- Assumptions underlying the projections and estimates should be clearly stated.

- Sensitivity of results to changes in key variables (e.g., oil price) should be shown.

- Take should be shown in terms of discounted as well as undiscounted cash flow.

- The effective royalty rate (or the minimum share the government may expect in any given accounting period) should be estimated.

- Ex post take estimates as well as ex ante take projections should be made available to the general public.

Disclosure of take analysis results by company or field will encounter various legal barriers at the company level. Thus, for both technical and administrative reasons, implementation of such reforms may be slow. However, where take projections and estimates can be easily prepared, their disclosure could be a good prima facie indicator of transparency. Take projections and estimates, it should nonetheless be emphasized, say nothing about the relative profitability of fields and should not be interpreted as setting a negotiating standard. Rather, making such data available to the general public could form one useful element of overall disclosure, which, along with other measures, should help improve the transparency of the fiscal regime. 
${ }^{34}$ See the general discussion of tax expenditures in the Manual. Defining the tax baseline for resource revenues is particularly difficult owing to the special tax arrangements (e.g., additional profit tax, royalties). It may therefore be best to consider the sector separately with a unique baseline. On this basis, tax deductibility of mandated social and environmental expenses will likely constitute the major element of state support through the tax system. ${ }^{35}$ Indonesia pioneered the use of PSCs in the oil sector, on the basis of a model contract and certain economic parameters biddable or negotiable. Indonesian PSCs have not changed significantly from one case to another, but following periodic revisions of the fiscal regime, different "generations" of model contracts have evolved. See discussion of this issue in Indonesia Fiscal ROSC, 2006, paragraph 11. ditures. ${ }^{34}$ For many countries, however, the regime itself is inherently complex and discretionary. The overriding transparency objective in such systems should be to move toward a clear definition of the fiscal regime, as well as reducing discretionary options.

\section{PSCs}

36. In principle, and by definition, PSCs are individually designed and the general underlying policies may be less clearly described in government policy statements or laws. As a practical matter, however, governments (or NOCs) usually make contracts under powers granted by general petroleum legislation and frequently negotiate and base their contracts on some form of model contract. ${ }^{35}$ It is possible for parameters in such contracts to remain undefined and thus open for bidding or negotiation, and many important elements of contract language are subject to case-by-case adjustment. Publication of model contracts may thus be of limited value in defining the fiscal regime, unless governed by clear policy statements or limitations in legislation regarding the variability of contracts. Publication of actual contracts will provide more definitive information, subject to the constraints outlined under licensing procedures above.

37. The main parameters of PSCs are the cost oil retained by the contractor to cover cost; profit oil, which covers the remaining production; and an agreed formula for dividing profit oil between the government (and/or NOC) and the contractor. The latter may be fixed or may be progressive according to production, price, or profitability criteria. Policy transparency would require that, where PSCs are the central instrument of the fiscal regime, all of the key PSC parameters should be available to the public in the same way as tax rates, exemptions, and deductions.

\section{Other elements of the regime}

38. Other elements that may be part of the overall policy framework include ring-fencing, indirect taxes, various forms of bonus and other nontax payments, fiscal stability clauses, and equity participation. These elements are discussed below.

\section{Ring-fencing}

39. Ring-fencing (a limitation on taxpayers' ability to consolidate income or deductions for tax purposes across different activities, projects, or license areas) has important implications for revenue flows and investor incentives. Its absence can postpone government revenue flows, because deductions from new projects can be offset against earnings from current production. But ring-fencing, in appropriate circumstances, can also help level the playing field for new entrants to a maturing resource project. In the longer term, absence of ring-fencing may yield higher government revenue by encouraging more exploration and development, at the cost of some additional risk 
to government revenue and some possible postponement of early revenues. From a transparency point of view, it is important that the government policies in this regard are clearly stated and that the system is applied uniformly and openly.

\section{Indirect taxes}

40. Indirect taxes may also play an important role in the fiscal regime. Resource sectors are often treated differently from other economic activities, either because of their special nature or as a fiscal incentive to attract investors. Indirect taxes provide an important source of early revenue to the government, but by the same token exemptions are also used as an investment incentive. For fiscal transparency purposes, the costs of any incentives provided through indirect tax exemptions (including import tariffs on intermediate inputs) should be clearly recognized, whether as part of the overall fiscal regime or separately calculated as tax expenditures.

41. Value-added tax (VAT) refunds present special problems. As Sunley, Baunsgaard, and Simard (2003) point out, zero-rating exports under a destination-based VAT will lead to continuous net refunding to exporters, which puts pressure on weak tax administrations, particularly in periods of high investment. VAT exemptions for imported capital goods and other inputs to the industry are therefore used by a number of countries to avoid the administrative burden of refunding, although it is difficult, especially for weak tax administrations, to separate inputs used by the resource industry from those used in other sectors of the economy. ${ }^{36}$

\section{Bonuses and non-tax payments}

42. Various types of bonus payment are used by many countries to collect early revenue from a project with little administrative effort. As indicated earlier, signature bonuses can be a key element of the fiscal regime at the licensing stage and are an effective tool for generating revenue early on. Where projects are high-risk and license deals are primarily negotiated, however, such payments are likely to be implicitly offset by concessions elsewhere (a trade-off that may well be justified in terms of government risk management). Bonuses paid prior to project development thus may have some of the characteristics of oil-backed loans, with an implicit repayment through future favorable tax treatment. Disclosure of contract terms in some form is therefore a necessary part of transparency. Various other forms of non-tax instruments (such as license, rental, or lease fees) are also used, but generally these appear to be relatively minor components of the overall fiscal regime.

\section{Fiscal stability clauses}

43. Investors naturally want to get as much assurance as possible that they will not be subject to unfavorable changes in the fiscal regime. To meet this requirement, many project agreements include fiscal stability clauses. There

\footnotetext{
${ }^{36}$ Sunley, Baunsgaard, and Simard (2003) and others also outlined the special problems faced in the countries of the Commonwealth of Independent States, which used to apply an origin-based VAT for oil and gas trade within the Commonwealth of Independent States but a destination-based VAT for other sectors. However, changes to these practices are under consideration.
} 
are various forms of such clauses, such as "freezing" the tax system at the time of the agreement or guaranteeing the investor take by compensatory adjustments to tax changes (in production shares, for example). On the one hand, such clauses can be administratively cumbersome and limit tax policy flexibility, although fiscal stability provisions can be designed to minimize the general tax policy impact. They also impair the legislature's normal authority to pass fiscal legislation. On the other hand, they may be necessary in high-risk environments and may increase the overall government take if they reduce investor risk premium. They may also make tougher policies elsewhere in the regime more acceptable than otherwise. At any rate, both the existence of such clauses and their potential implications should be clearly explained to the public.

\section{Authority over Revenue Flows and Borrowing}

Fiscal authority over resource-related revenue and borrowing should be clearly specified in the law. Legislation should include a requirement for full disclosure of all resource-related revenue, loan receipts and liabilities, and asset holdings.

44. The budget process should handle resource-related revenues similarly to other government revenues, and any law governing the receipt of such revenues and appropriation for spending should be consistent with the law governing the government budget. In practice, it is often the case that laws governing company payments are first executed outside the finance ministry. For example, a royalty is usually imposed by petroleum or mining legislation and collected by the ministry or agency responsible for the legislation; similarly, an oil PSC is most often made either with the petroleum ministry or with the NOC. The ministry responsible for fiscal policy, however, should have a guiding influence on the level of such payments and the design of the overall fiscal regime. Moreover, resource industry laws should be consistent with general budget and tax laws.

45. To the extent that resource revenue payments are received by an NRC, a resource-related fund, or local governments, the rationale for such arrangements should be made clear. Good practice is that all such revenues should flow to the government budget before being appropriated for spending purposes.

46. Rights to borrow for public purposes should be under the authority of the finance ministry on behalf of the government. Receipt of such borrowings should be credited to a bank account under the control of the finance ministry or its treasury, with the balances credited, liabilities incurred, and terms of loans being fully disclosed to the public. The basis for transparency in this regard is, first, an adequate legal framework that specifies authority to borrow clearly and requires adequate disclosure and oversight mechanisms. Second, the legal framework must be adequately observed and oversight bodies should have adequate authority and capacity to administer the law. Borrowing or collateralization by an NRC should be similarly transparent, given the likely 
significant fiscal implications of such borrowings. However, in a number of resource-rich developing countries, practice often departs substantially from such standards: loans may be made on the basis of future production collateral, generally on a negotiated rather than open tender basis; the terms of loans are often not fully available to the public; and the authority for such borrowing may not be subject to the usual rules of financial management and oversight by the finance ministry and the national audit office.

47. Resource-related asset holdings should also be subject to clear rules for disclosure, regardless of whether they are held by the finance ministry, a separate resource fund (see below), or any other entity. Equally important, these assets should be considered as part of government's overall financial assets, with changes considered as part of the overall fiscal balance (see Chapter III). To the extent that a full government balance sheet is maintained, the assets should be reported as part of the consolidated government balance sheet. ${ }^{37}$

\section{Equity Participation}

1.1.5/1.2.4

Government involvement in the resource sector through equity participation should be fully disclosed and the implications explained to the public.

48. As indicated above, direct government equity participation in projects to develop resource sectors is an important element of the fiscal regime in a number of resource-rich countries. Sunley, Baunsgaard, and Simard (2003) indicate that 18 of the 40 emerging or developing countries covered by their survey participated, or had the right to participate, directly in resource ventures. Maximum equity stakes in these countries ranged from 5 to 50 percent. Governments can acquire equity under normal commercial terms or through various forms of concessionary purchase, including tax swapped for equity and so-called "free" equity. A common way is through what is called a "carry"-where the government- "carried" equity interest is financed by private investors, but, after commerciality has been established, the government contributes to sunk project costs to a varying extent from its share of the profits or profit oil. ${ }^{88}$ In addition, some systems allow the government an option to buy into a project at the time of discovery. Generally, however, favorable terms for the government's participation involve some form of offsetting reduction elsewhere in the fiscal regime. All such concessions and their costs should be disclosed as completely as possible.

49. If, as is commonly the case, the government has the right to take up a working interest through the NRC (in some cases paid by the NRC share of profit oil) or the resource ministry, there should be full disclosure of the form of payment and ownership arrangement. ${ }^{39}$

50. Where the bulk of production is under direct state control, payments to the budget would occur as taxes and dividends or as other forms of income, including the proceeds from direct domestic and external sales of oil or any other resource products. Good corporate governance practice would require that NRC accounts statements be available to the public and the policy on dividends be disclosed. As discussed further below, however, few NRCs cur-
${ }^{37}$ These recommended practices are in line with the requirements under the Government Finance Statistics Manual 2001 (IMF, 2001a).

${ }^{38}$ Daniel (1995) notes that carried interest is, under certain assumptions, fiscally equivalent to a resource rent tax and, more generally, describes the fiscal equivalence of various forms of state equity participation and production sharing arrangements. ${ }^{39}$ In a few countries, the working interest share granted to the "government" is actually held by individuals (typically government officials). Such a delegation appears prima facie inherently transparent, and the rationale for such practices should be fully disclosed. 
${ }^{40}$ For example, McPherson (2003) notes that NOCs control 90 percent of world oil reserves and account for 73 percent of production.

${ }^{41}$ See McPherson (2003).

${ }^{42}$ For transparency, best practice would be to eliminate QFAs and provide any subsidies directly in the budget. Good practice for fiscal transparency requires at least a clear description of QFAs with an explanation of their role in overall fiscal policy. Although the Norwegian model described below offers one example of clarity, it is not suggested that this is the only possible transparent arrangement. Specific examples of QFAs carried out by NRCs are discussed in the next section. rently meet these standards. Compliance with EITI would require considerably more effort to apply these.

\section{E. National Resource Companies}

1.1.4/1.1.5

Ownership structures of national resource companies and their fiscal role vis-à-vis the resource sector ministry and the finance ministry should be clearly defined.

Commercial responsibilities should be clearly distinguished from policy, regulatory, and social obligations.

51. NRCs have become increasingly important players, especially in the oil sector. ${ }^{40}$ Government ownership and control of resources gained increasing importance in the 1970s, with an initial focus on nationalization and control of upstream activities. Subsequently, governments of both oil-exporting and oil-importing countries began creating national companies to promote downstream activity; one key aim of this was to gain control over petroleum retail pricing. This led to a rapid expansion of national companies' role in setting petroleum policy, including the adoption of a variety of noncommercial policies usually associated with the government. The ability of these companies to attract available local (as well as international) expertise, and the greater flexibility of company structures, led in many countries to a corresponding decline in the quality and authority of traditional general government. Although in more recent years there has been a critical reevaluation of the role of NOCs in recognition of their manifold weaknesses, they continue to have a powerful influence on policy in many developing and transition countries. ${ }^{41}$ As discussed under practice IIIC, there may be a case in some countries for considering a broad public sector balance including the NRC as a key indicator of fiscal policy.

52. Two issues that have a direct bearing on fiscal transparency for all NRCs are discussed in McPherson (2003):

- Commercial and noncommercial activities should be clearly separated. Poor commercial performance may in part be attributed to poor governance and lack of competition, but the companies' substantial role in promoting a variety of noncommercial/quasi-fiscal activities (QFAs) reduces managerial accountability for both types of activity. Provision of noncommercial services is primarily a government responsibility, and clarity of fiscal policy requires that the extent of such activities be overseen by the finance ministry. ${ }^{42}$

- Policy and regulatory roles vis-à-vis the sectoral ministry and the finance ministry should be clearly defined. These problems are minimized when these companies focus primarily on commercial activities.

53. Substantial reform of management of NRCs is needed to address these issues adequately. At the same time, better disclosure of the ownership structures of these companies and their subsidiaries is a central element 
of corporate governance. ${ }^{43}$ Such disclosures should include, if applicable, share participation of government officials and more general governance issues (e.g., composition of board, audit practices). The government's policy and administrative roles usually need to be more clearly defined as well. Addressing capacity and institutional constraints in these areas is critical for reforming resource transparency and management in developing countries. The "Norwegian Trinity Model" provides one model of a clear definition of roles. ${ }^{44}$ In many ways, policy and administrative reforms are necessary precursors to implementing improvements to many other elements of transparency and resource management, because most such improvements rely on establishing clear lines of accountability.

\section{F. Quasi-Fiscal Activities of Resource Companies 1.1.4/1.1.5}

Arrangements whereby international or national resource companies undertake social or environmental expenditure or provide subsidies to producers or consumers without explicit budget support should be clearly defined and described in the budget documents.

\section{Economic and social QFAs}

54. State-owned enterprises and government institutions as well as the central bank can undertake quasi-fiscal activities. ${ }^{45}$ The existence of QFAs means that the budget gives a misleading picture of the actual extent of fiscal activity and, as discussed above, leads to a blurring of responsibility between the government and state-owned enterprises. These issues are discussed extensively in the Manual but they are particularly relevant for resource-rich countries in which government responsibilities are transferred to sector agencies where both financial and managerial resources are concentrated. ${ }^{46}$ With respect to resource sectors, the main types of QFAs include the following:

- Energy QFAs: requirements for NRCs to provide products (particularly energy) at less than cost recovery or market price for domestic consumption;

- Public expenditure QFAs: requirements for NRCs or international companies to provide social services or other public goods normally provided by general government;

- Employment QFAs: provision of employment in NRCs or related activities that go beyond what would be done if companies were run on a purely commercial basis; and

- Borrowing QFAs: use of company leverage to borrow on behalf of government.

55. Energy QFAs cause market distortions and understate the size of government activity and the size of the budget deficit. In particular, providing energy at low prices represents an implicit, untargeted subsidy that invites overconsump-

\footnotetext{
${ }^{43}$ See discussion of OECD Principles of Corporate Governance in the Manual. ${ }^{44}$ Policy and licensing as well as petroleum taxation and related fiscal issues are the responsibility of the government of Norway (e.g., Ministry of Petroleum or Ministry of Finance). The Petroleum Directorate provides advice to the Ministry of Petroleum (to which it reports) on technical matters, manages technical data, and enforces technical regulations. The NOC (Statoil) focuses on commercial operations, a role recently reinforced through partial privatization. See McPherson (2003, p. 200).

${ }^{45} \mathrm{~A}$ broad definition would include all operations that could in principle be duplicated by specific budgetary measures in the form of an explicit subsidy or direct expenditure. Typical QFAs with critical macroeconomic significance include multiple exchange rate regimes, the provision of exchange rate guarantees, nontariff trade barriers, credit rationing and directed lending at below-market interest rates, and the provision of goods and services by state-owned enterprises at below-market or cost recovery prices.

${ }^{46}$ Statements on quasi-fiscal activities are essential for fiscal transparency. These statements should, at a minimum, indicate the purpose of each quasi-fiscal activity, its duration, and the intended beneficiaries. In addition, there should be at least some assessment of the potential fiscal significance and, where possible, quantification. See Chapters I and III of the Manual for further details.
} 
${ }^{47}$ Analytically, an important distinction needs to be made between short-run marginal costs and long-run marginal costs (i.e., including investment). Ideally, tariffs should be determined on the basis of the latter.

${ }^{48}$ In the past, this was a common feature in a number of energy-rich former Soviet Union countries. For detailed analyses of energy sector quasi-fiscal activities stemming from implicit subsidization of oil and other energy products, see, for example, Petri, Taube, and Tsyvinski (2003). ${ }^{49}$ See Gupta and others (2003); Petri, Taube, and Tsyvinski (2003); and Taube (2001). ${ }^{50}$ This was, for instance, one reason why Angola's Sonangol took over the responsibility for various economic, social, and financial activities from the central government during Angola's protracted civil war.

${ }^{51}$ Technically, a QFA only exists if the company is acting at the direction of government. In some cases, resource companies may decide to provide a noncommercial service or good simply for purchase of goodwill in the local community. Even if this is the case, the amount spent for such activities should be identified in the company's financial reports and also in the budget to reveal the full expenditure for the public good or service in question.

(continues on next page) tion and waste by households, enterprises, and other users, with a potentially large adverse environmental impact. Maintaining such subsidies leads to a misallocation of resources and risks the creation of an unsustainable dependence on continuing low energy prices. Such QFAs are prevalent in many energy-rich countries. The previous section noted additional consequences in terms of reducing managerial accountability for both commercial and noncommercial activities.

56. Energy QFAs come in various forms and may involve international companies as well as NRCs. Generally, most important among these is, as indicated above, the provision of petroleum or other energy products through state-owned enterprises at nonmarket prices that, in some cases, do not cover even operating costs. ${ }^{47}$ Sometimes, de facto subsidies to consumers are even higher if energy parastatals tolerate the accrual of arrears by consumers. ${ }^{48}$ In the oil sector, a particular type of QFAs are what is called "Domestic Market Obligations" (DMOs). These often require (foreign) oil companies to sell a certain share of crude oil production domestically below market price. Such arrangements should be disclosed as part of the government's energy policy, which often also includes administrative pricing rules for petroleum and other products. Energy QFAs owing to low prices and the tolerance of arrears can be very large. For example, implicit subsidies of petroleum products because of unduly low prices were estimated at 3.5 percent of GDP on average in 1999 for a group of 15 oil-exporting countries, with wide variations across countries. Some of the highest oil-related implicit subsidies were measured for the Islamic Republic of Iran (17 percent of GDP in 1999-2001) and Azerbaijan (more than 20 percent of GDP in 2000). ${ }^{49}$

57. Public expenditure QFAs involve national resource companies or international companies taking responsibility for services or public goods that are normally provided by general government. This may have been justified by government on the grounds that these activities represent a desirable partnership between companies and government to serve the needs of society. In some cases, it is argued that a company is better placed to provide services to, say, remote communities than is the government. ${ }^{50}$ Moreover, companies themselves may feel that they enjoy benefits through better reception by the communities affected by the resource development. ${ }^{51}$ Such activities, however, are rarely reported clearly or comprehensively. The extent of government fiscal activity is thereby understated, which may also generate inefficiencies.

58. The main transparency point is that the extent of such activities and their justification should be clearly explained in the budget process. Budget documents should explain clearly the nature of the expenditures and how costs are shared between the government and companies-including through the tax treatment of such expenses. ${ }^{52}$ Coverage and explanations of QFAs in budget documents should be nondiscriminatory, that is, relevant activities should be covered regardless of company ownership (private or state-owned).

59. The financing and provision of social services (e.g., local schools or health clinics), infrastructure, or other services for local communities may or may not be fixed in contracts between the government and individual companies. Such spending may be beneficial from a development perspective because it helps fight poverty and improve infrastructure, especially in regions and sec- 
tors where government implementation capacities are weak. However, it may also result in direct costs for the government (e.g., recurrent costs after the end of the mining project) and could distort overall public spending priorities.

60. To the extent that spending for such programs is cost recoverable or tax deductible by resource companies, the government is burdened with part of the costs for these activities. For instance, if 40 percent of all spending on social and community programs by a resource company project is tax deductible, the government effectively and implicitly subsidizes these activities to this extent through forgone revenue. ${ }^{53} \mathrm{~A}$ case in point is the "Infrastructure Tax Credit Scheme" for mining companies in Papua New Guinea. In recognition of local governments' limited capacity to implement social service and infrastructure projects, it was agreed that licensed mining companies would finance and implement development projects (e.g., schools, health facilities, roads) up to a maximum amount ( 0.75 percent of the value of gross sales) and receive in exchange an income tax credit for these expenses.

61. Employment QFAs are similar in principle but involve less easily defined costs and social aims. A fairly common example is the provision of employment opportunities in NRCs over and above what would seem required for commercially run enterprises. The requirement for national or international companies to provide training to local counterparts, hiring quotas, and local content requirements can also be considered quasi-fiscal activities because they result in higher costs and hidden taxes for companies than under a pure market environment. ${ }^{54}$

62. Borrowing QFAs ${ }^{55}$ are equally an extension of NRC fiscal authority outside normal channels. The costs, however, are in terms of diffusion of financial management authority and hard to quantify. Such arrangements signify a need to clarify the relative roles of the national resource company and the finance ministry.

\section{Environmental and site abandonment issues}

63. Extractive industries invariably have a significant impact on the environment. Environmental expenses differ from QFAs in that they are seen as a partial obligation of the resource companies because they are fundamentally linked to the production process. Nonetheless, at least part of these expenses will be tax deductible and hence the costs partially borne by the state; it is important that the level of expenditure on environmental protection be captured in fiscal documents and publicly reported alongside other public spending. Increasingly, these concerns are being built into general and industry-specific legislation as well as individual contracts. Whereas, a decade ago, oil PSCs often did not include proper site restoration and cleanup provisions, these are becoming standard features.

64. In many respects, however, such issues are but one facet of the overall negotiations between governments and companies. Ownership of the resource ultimately generally rests with the government, and from a purely commercial company perspective, the cost of protecting the environment or restoring the site is both a government responsibility and part of the overall cost structure. For any company, this component must therefore be included
${ }^{52} \mathrm{On}$ this point, two kinds of relationship can be distinguished: (1) it may be agreed that the provision of, say, schools and health facilities for company employees in remote areas is a necessary business expense and tax deductible; or (2) government and companies may agree as a matter of policy that companies should provide certain social services normally considered a government responsibility, in which case either costs are tax deductible or a tax credit is given (as in the case of Papua New Guinea, described in paragraph $60)$. Both types of arrangement should be reported as part of overall fiscal activity. In the second case, revenue forgone by government should be estimated and reported as a tax expenditure in the budget documents.

${ }^{53}$ Best practice for transparency would require the budget to include a subsidy to the company to cover the full cost of the mandated expenditure. However, if the expenditure is fully or partially offset by a reduced tax liability, it would be important for the budget to describe the full nature of the arrangement, including the full cost of the QFA and the amount of revenue forgone because of a tax deduction or other exemption (i.e., the associated element of tax expenditure).

${ }^{54}$ For example, as part of the development of the Indonesian oil sector, a Utilization of Expertise and Skill Development Fund was established with the objective of encouraging local hiring. The fund is financed with obligatory payments of $\$ 100$ / month per expatriate employee. ${ }^{55}$ McPherson (2003) cites Angola's Sonangol as an example. The Global Witness report "Time for Transparency" also provides examples from other countries (Global Witness, 2004). 
${ }^{56}$ Norway again provides a good example of a comprehensive approach. The Norwegian government cooperates closely with industry to ensure development is associated with environmental protection at all stages of development. Norway accepts its obligations under the Kyoto protocol and is applying a range of instruments accordingly. See http:// www.regjeringen.no/upload/ kilde/oed/bro/2005/0004/ddd/ pdfv/243848-miljo_05_engelsk.pdf. ${ }^{57}$ Contract provisions often allow for the accrual of an abandonment fund during the life of a project. Responsibility for site restoration should be clearly specified, and for transparency purposes contracts should specify the starting point (e.g., after 30 percent depletion), time profile of payments, and accrual mechanism (e.g., through an escrow account) and make provision for reassessment of the restoration liability. These practices are increasingly recognized as necessary company costs of resource extraction.

${ }^{58}$ For example, in Nigeria the state and local governments are not required to report on budgets and their execution to the federal government. Data on subnational government activities are available only through an annual survey carried out by the Central Bank of Nigeria, and the quality of these data is limited.

${ }^{59}$ Related to this point, a weak government increases the difficulty of developing a coordinated macroeconomic policy for stabilization and savings. in overall project costs and thus taken into account in profit calculations. The question is how such costs are shared between the company and the government, through cost recovery or tax deduction, and over what period of time. Socially and environmentally, it is, of course, essential that such costs be clearly recognized and reported and that steps to address the issues be built systematically into individual project design-with appropriate and efficient sharing of costs between the government and companies. In advanced countries, these factors are reflected in the legislation and applied through the general tax system and specific project agreements, ${ }^{56}$ though even in such countries, there is often scope to improve reporting on implicit state support of environmental spending through the tax system. ${ }^{57}$

\section{G. Subnational Government and Resource Revenues}

Arrangements to assign or share resource revenues between central and subnational levels of government should be well defined and explicitly reflect national fiscal policy and macroeconomic objectives.

65. The assignment of taxation powers and expenditure responsibilities to central and subnational governments should be based on stable principles and agreed-upon formulas, which should be clearly and transparently formulated and implemented as legally prescribed, in an open and consistent manner. These general requirements are particularly important in large, diverse, decentralized countries that have sizable oil or other natural resource revenues. At the same time, however, when subnational jurisdictions are fiscally important and enjoy a large degree of independence from the central government, it is a considerable challenge to establish a sound and transparent subnational revenue sharing system. This challenge is much greater in such countries when state and local government fiscal operations do not provide good fiscal data regularly and in a timely manner. ${ }^{58}$

\section{Economic and fiscal policy considerations}

66. Economic theory suggests a number of reservations with regard to giving oil or other large natural resource revenue to local governments, in particular if combined with resource-related taxation powers. In practice, however, resource revenues are playing an increasing role in financing subnational governments worldwide. Assigning revenue to subnational governments is generally considered likely to improve accountability and the quality of spending because local governments can determine better than central governments the needs and requirements of their populations. However, the "resource curse" arguments advanced at a national level (see Overview) are likely to apply equally, if not more strongly, to weak subnational governments. From a macroeconomic and sustainability perspective, the most important argument is that a central government will be able to exercise the needed authority to strictly control spending and save windfall revenue. ${ }^{59}$ Another 
argument in support of natural resource revenue accrual at the central government level is the need for policy coherence; because energy sector policies are usually under the jurisdiction of the central government, government tax and expenditure policies related to natural resources should also be determined at this level.

67. However, despite such arguments, controls over resource revenue are often decentralized. In some countries, subnational governments own the natural resources. ${ }^{60}$ In others, constitutions or basic legislation require that natural resource revenue be shared with subnational governments, often reflecting political economy considerations. ${ }^{61}$ Measures other than direct revenue sharing can be taken to balance centralization of resource revenue collection. For example, nonresource taxes can be assigned to subnational governments to provide them with some autonomy. Fiscal management and equity factors also generally require that a transfer system be put in place to address vertical imbalances between the central and local governments as well as horizontal imbalances across local governments (Ahmad and Mottu, 2003).

68. Because natural resources tend to be distributed highly unevenly across regions, it is difficult to base horizontal revenue allocation on the "origin principle," as this would intensify regional imbalances. The following examples illustrate these difficulties. In Indonesia, implementing this principle would imply that five provinces would likely receive 80 percent of the local share in oil and gas revenue, whereas the remaining 25 provinces would each receive very little. ${ }^{62}$ In Argentina, three provinces (with only 3 percent of the population) produce nearly three-fourths of total oil output. Some similar factors apply in Russia, where the five oil-richest regions have only 6 percent of the population but collect over 50 percent of all subnational government revenue related to natural resources. ${ }^{63}$ In this last case in 2006, however, about 96 percent of oil revenue was assigned to the federal government. The case for equalization transfers into nonresource-producing regions needs to be examined in the context of the overall assignment of oil revenues in each country. ${ }^{64}$

69. Existing revenue sharing systems can be categorized within a spectrum ranging from full centralization to full decentralization, with a variety of tax and revenue-sharing arrangements in between. ${ }^{65}$ Also, revenue sharing can be applied (i) across taxes (e.g., assignment of all royalties to provinces in Papua New Guinea), (ii) on the basis of providing a share of all resource-related revenue, or (iii) on the basis of expenditure needs of local governments. Whereas smaller countries tend to fully centralize oil revenue, larger countries, especially those with a federal structure, typically adopt some form of subnational revenue-sharing arrangement (e.g., Colombia, Ecuador, Indonesia, Kazakhstan, Mexico, Nigeria, Russia, and Venezuela). ${ }^{66}$ Mexico has established a revenuesharing formula that has a broader revenue base, that is, it includes not only natural resource revenue sources but also indirect taxes.

70. Generally, there appears to be a trend toward an intensified use of subnational revenue sharing, as is demonstrated for example in Indonesia, which changed from a centralized model to a decentralized revenue-sharing model in 2001. Other countries, including Papua New Guinea, the Philippines, and Nigeria, also have subnational revenue-sharing systems. In Bolivia, there is
${ }^{60}$ For instance, Australia, Canada, and the United States, where provinces or states and (in some cases) private landowners can possess natural resources. In these countries, strong measures of control and transparent practices at the subnational level have contributed to the successful management of resource revenues.

${ }^{61}$ In a number of countries, oilproducing regions have pushed for independence over this issue, which at times has resulted in unrest, war, and secession (e.g., the Biafra war in Nigeria, Aceh in Indonesia). Following these conflicts and continued tension, both the Nigerian and Indonesian central governments agreed to establish natural resource revenue sharing arrangements. Nigeria now distributes 13 percent of oil revenue to oil-producing states. Indonesia allocates 55 percent of oil revenue and 40 percent of gas revenue to Aceh province. In Chad, 5 percent of oil revenue is assigned to oil-producing regions. ${ }^{62}$ In practice, a variety of factors are taken into account in Indonesia within a broad system of intergovernmental transfers. Revenues collected by the central government on account of property tax, personal income tax, and natural resources (e.g., oil, gas, forestry, and mining) are shared with subnational governments according to specified rates. See Indonesia Fiscal ROSC, 2006, paragraphs 11 and 12, for further details and discussion of issues associated with resource revenue sharing.

${ }^{63}$ Martinez-Vazquez and Boex (2000).

${ }^{64} \mathrm{Ahmad}$ and Mansoor (2002) describe such a horizontal equalization scheme in Indonesia.

${ }^{65}$ For oil-producing countries, these systems are analyzed in detail by Ahmad and Mottu (2003). 
${ }^{66}$ There is also the special case of the "full decentralization model" in the United Arab Emirates. Oil revenue accrues to the individual emirates and is then upwardly shared with the UAE government based on a negotiated formula. Canada and the United States share revenue bases between provinces and states on the one hand and the federal government on the other hand. pressure to reverse changes to the hydrocarbon revenue allocation system, which were designed to give a higher revenue allocation to subnational governments, especially provinces that produce oil and gas.

\section{Fiscal transparency guidelines}

71. Clear rules and principles should guide whatever subnational revenue-sharing arrangement is chosen. Moreover, tax powers, revenue-sharing arrangements, and expenditure responsibilities should be based on stable principles and agreed formulas that should be developed and exercised in an open and consistent manner. These principles should include not only understandings between the various levels of government on the original arrangement, but also rules and procedures for modifying it. Regarding the latter, Brosio (2003) has suggested the sound rule that as long as renegotiations of the subnational revenue-sharing system take place, the original system continues to be in place and no party holding a stake should have a veto power to stop the existing system from functioning. 


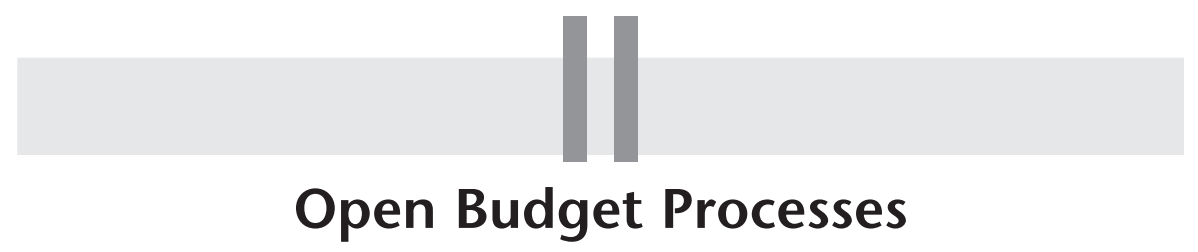

72. Similar principles of transparency to those recommended for other parts of the government budget should apply to the processes for planning, allocating, spending, and reporting resource revenues. The special features of resource revenue, however, require that governments give particular emphasis to policy clarity with regard to explicit treatment of risks arising from the resource base, transparency of accounting, and control of receipts and spending. In particular, the government should clearly explain to the public its policies toward smoothing the impact of volatile revenue flows and ensuring long-term fiscal sustainability. If savings or stabilization funds have been established, they should be fully integrated into the overall fiscal policy framework. All resource-related asset holdings should be fully disclosed and asset management policies open. This section covers these and other good transparency practices that will lead toward an effective application of fiscal policy in resource-rich countries.

\section{A. Fiscal Policy and Resource Revenues $\quad 2.1 .2 / 2.1 .4 / 3.1 .7$}

The budget framework should incorporate a clear policy statement on the rate of exploitation of natural resources and the management of resource revenues, referring to the government's overall fiscal and economic objectives, including long-term fiscal sustainability.

73. Governments benefiting from large flows of revenue from exploitation of natural resources face a range of issues that need to be explicitly considered for fiscal transparency. First, revenues are subject to high and unpredictable price volatility, with potentially destabilizing budgetary and liquidity effects. Second, because the resources are finite, it is important to take into account alternative options concerning possible exploitation rates and the intergenerational distribution of income flows, as well as the distribution of spending and the immediate social impact of resource industries. Third, the economic impact of large inflows of resource revenues needs to be carefully considered in light of possible "Dutch disease" effects, characterized by an appreciating 
${ }^{67}$ Colombia has implemented a medium-term fiscal framework that informs the annual budget process.

${ }^{68}$ Some countries, such as

Botswana, Indonesia, and Malaysia, have used national development planning processes relatively effectively to set medium- and long-term priorities.

${ }^{69}$ See IMF (2007b), which describes the elements of medium-term frameworks. It notes, however, that although such frameworks are the norm in OECD countries, low-income countries have experienced mixed results to date. real exchange rate and the associated adverse impact on the nonresource tradables sector of the economy.

74. A clear framework for government policy that recognizes all of these issues is an essential basis for design of an effective and transparent fiscal management system in resource-rich countries. The requirements in the Code for budgeting to be conducted in a medium-term macroeconomic and fiscal policy framework (practice 2.1.2) and for governments to publish a periodic report on long-term finances (practice 3.1.7) are therefore particularly compelling for resource-rich countries because they clarify the range of fiscal policy options arising from prospective resource revenues. Fiscal sustainability issues (practice 2.1.4) also need to be directly addressed, with a clear account of the sensitivity of the sustainability analysis to different assumptions about exploitation rates, export prices, and other economic variables.

75. Development of a medium-term framework and long-term fiscal sustainability analysis should be within the capacity of all countries, although the depth of detail may be constrained initially by the capacity of the public financial management system. ${ }^{67}$ For some countries, they may need to be implemented gradually. ${ }^{68}$ Elements that are particularly important for resource-rich countries are the following: ${ }^{69}$

- Establishment of a medium-term fiscal framework (MTFF), with a comprehensive statement of fiscal policy objectives, broad medium-term macroeconomic projections (based on clearly stated and realistic assumptions), and aggregate fiscal targets;

- Identification and regular analysis of major fiscal risks to the fiscal position and budget policy (including macroeconomic risks, control risks, and contingent liabilities);

- Regular reviews of long-term fiscal sustainability, focusing on resource production and price expectations; and

- An open process for setting budget spending priorities.

76. To ensure that the sustainability of fiscal policies is comprehensively addressed, the medium-term framework needs to incorporate all extrabudgetary funds, quasi-fiscal activities, and tax expenditures. Such a framework is most effective in the context of a unified budget and the use of risk management strategies. Publication of the medium-term projections, including the policy and economic assumptions used in the framework, is crucial in helping the public understand the future implications of current fiscal policies.

77. A medium-term fiscal policy framework and long-term assessments of public finances should assist in evaluating the implications of planned expenditures for future expenditure priorities and assessing the associated risks for sustainability. For example, both social entitlement and investment programs, which newly resource-rich countries might want to expand substantially, involve multiyear spending commitments and can increase budget rigidity. Also, although investment programs carry substantial implications for future recurrent costs, many resource-rich countries maintain capital budgets that are separate from recurrent budgets. Under such "dual budgeting" 
conditions, the planning and execution of each budget is separate, and the implications for later recurrent spending are not part of the decision-making process. Linking annual budgets transparently to medium-term plans and priorities helps ensure that resources for capital and recurrent expenditure are not overcommitted in the short term, allowing greater flexibility subsequently in responding to variations in resource revenues and other shocks. It can also encourage realistic appraisals of the impact of investment programs on economic growth.

78. OECD best practice guidelines suggest that a long-term report (1040 year projections) assessing the sustainability of current fiscal policies be published every five years, with more frequent publication if there are major expenditure or revenue policy changes. ${ }^{70}$ For resource-rich countries, longterm reports should contain scenarios that allow for the return of commodity prices from transitory swings to longer-term trends. Because the longer-term horizon is subject to greater uncertainty, it is also important to provide appropriate sensitivity analysis showing the impact of different assumptions about economic variables, including the relative prices of commodities and alternative exploitation and taxation policies.

\section{B. Fiscal Policy, Resource-Related Funds, and the Budget}

Mechanisms for coordinating the operations of any funds established for resource revenue management with other fiscal activities should be clearly specified.

79. Many countries have established separate funds for resource revenues, either to channel resources for development investment or to promote saving to help address the stabilization and sustainability issues of large, volatile, and exhaustible revenue flows. Such funds need to be closely integrated with the budget, so that they clearly operate in a manner that supports the government's overall fiscal policy and resource allocation. This requires that projections of transactions, and accounts giving details of actual spending by the funds, and their assets and liabilities, are presented to the legislature as part of the budget process, along with standard budget reports and accounts. Funds should ideally not undertake domestic expenditure directly because of the dangers of generating a "dual budget" and reducing fiscal transparency. Resource-related funds are best managed as an integral part of the mediumterm fiscal policy framework to help ensure that expenditure plans are set within a sustainable path. Stringent mechanisms should also be in place to ensure efficiency and integrity in the management of assets and use of resources and to provide assurances of transparency, good governance, and accountability. ${ }^{71}$

80. Experience to date with stabilization and savings funds has been mixed. Two examples of countries with successful and transparent national funds are Botswana (for diamonds-see Box 3) and Norway (for oil). ${ }^{72}$ The operation of the Norwegian Pension Fund-Global (NPFG, formerly known

\footnotetext{
${ }^{70}$ See the Manual, Chapter III, practice 3.1.7.

71IMF (2007b) notes that the quantitative analysis shows no evidence that the introduction of oil funds or fiscal rules has an impact on fiscal outcomes, including in containing spending, controlling for relevant factors.

${ }^{72}$ Hannesson (2001) also looks at subnational funds, including Alaska in the United States and Alberta in Canada.
} 


\section{Box 3. Botswana's Prudent Management of Mineral Wealth}

Diamond mining in Botswana started in the early 1970s, and the country has been a key player in the world diamond market since the 1980s. Diamonds are Botswana's major natural resource, accounting for about a third of GDP, threefourths of exports, and more than half of government revenue. Diamond mining is carried out by the private sector, but with significant government shareholdings in mining ventures, with foreign investors the other major shareholders. Mining agreements typically last for 25 years and marketing arrangements for 5 years, providing a stable and reliable framework for investors and the government. By some estimates, Botswana's government takes about 75 percent of diamond mining profits through taxes, royalties, and dividends. The tax legislation is considered transparent, relatively simple, and characterized by low tax rates (e.g., the corporate tax rate has been reduced to 15 percent).

Botswana has achieved strong real GDP growth over a prolonged period of time (on average, almost 9 percent since the 1970s), reaching a per capita income of $\$ 3,500$ in 2000 . Inflation has generally been low, and large fiscal and current account surpluses have been recorded in many years. Foreign exchange reserves have been rising to more than $\$ 5$ billion and, despite some decline in recent years, still amount to about two years of imports, while external debt is below 10 percent of GDP. Botswana has been awarded investment-grade sovereign debt ratings. Political and economic stability has helped greatly to attract substantial foreign direct investment across major economic sectors (Basu and Srinivasan, 2002). Prudent policies have also helped in recent years to master external shocks, such as a regional drought, a decline in diamond demand, and a significant depreciation of the South African rand, the currency of Botswana's biggest trading partner.

Within a stable political system, Botswana has pursued broadly coherent and prudent economic policies over long periods of time, dealing effectively

${ }^{73}$ See Davis and others (2003) and Skancke (2003).

as the Norwegian Petroleum Fund) can be considered as best practice for a resource-related fund, because it forms part of a coherent fiscal policy strategy. The strategy has two central pillars: first, it aims at smoothing public spending over time and decoupling it from volatile oil revenue; second, it seeks to replace oil wealth with financial assets, which are expected to grow in value over time, so as to be able to deal with the expected increase in public spending associated with an aging population (Skancke, 2003). Importantly, Norway's fiscal policy drives the operation of NPFG rather than vice versa. NPFG accumulates all oil revenue and returns on financial investments, and it makes transfers to the budget only to the extent necessary to finance the nonoil deficit, which is determined by annual, medium-term, and long-term fiscal policy objectives. NPFG is thus characterized as a financing fund; stabilization and sustainability objectives are achieved by fiscal policy, not by NPFG.

81. Whereas part of the explanation for Norway's success with NPFG lies in the country's historical strengths (a well-established institutional framework, a long tradition of fiscal and central banking transparency, and a broad revenue base), other countries are setting up funds precisely because they lack such advantages. ${ }^{73}$ For example, Wakeman-Linn, Mathieu, and van 
with large, variable diamond revenues, thereby avoiding the "resource curse" (Acemoglu, Johnson, and Robinson, 2003). Mostly appropriate monetary policies have contained inflation and stabilized the exchange rate, helping avoid real appreciation and a loss in competitiveness ("Dutch disease"). Fiscal policy has been the main tool for macroeconomic management. Public spending has increased strongly in many years, but these increases have not generally been excessive. Significant shares of diamond revenues have been saved over many years, adding to the country's foreign exchange reserves and effectively sterilizing the liquidity impact of large external diamond revenue inflows. The government's external reserves are managed prudently and transparently by the central bank and invested through the Pula Fund ( 80 percent) in long-term assets and the Liquidity Fund (20 percent) in the money market and short-term bonds.

Medium-term national development plans (NDPs) have been a key fiscal policy instrument for channeling diamond revenues into capital investments. The NDPs have some features of medium-term expenditure frameworks. They have generally been implemented in a disciplined fashion. Through public and private investments, the country has significantly expanded its physical infrastructure (e.g., roads, energy, health facilities, schools), although public investments have not always been of good quality. Before the HIV/AIDS pandemic began to spread, remarkable progress in social development had been made. NDPs have generally been formulated with a view to maintaining a sustainable fiscal position, as measured by the "sustainability ratio" (Modise, 2000; and IMF, 2004), defined as the ratio of noninvestment current spending (excluding health and education, which are considered as investment in human capital) to nonmineral revenue.

Selm (2003) outline the political economy case that appears to have been behind the establishment of funds in Azerbaijan and Kazakhstan (and likely more generally) that quarantine resource revenues, to a greater or lesser extent, from the rest of the budget. Essentially, the argument is that a separate fund with clearly defined policy objectives can protect some portion of resource revenue more effectively from political pressure and potential waste and corruption than the government budget can. ${ }^{74}$ Where the budget environment is nontransparent and administration is weak, such an argument has some merit, but such funds should still be integrated within a consistent fiscal policy framework-along the lines of the Norwegian model. This requires explicit procedural and operational rules, as discussed in the following section. 75

\section{Operations of Resource-Related Funds}

2.1.2

Operational rules applied to resource-related funds should be clearly stated as part of an overall fiscal policy framework.
${ }^{74}$ The need to develop a viable non-oil enterprise sector and avoid Dutch disease was also seen as particularly important in these transition economies.

${ }^{75}$ As noted in The Role of Fiscal Institutions in Managing the Oil Revenue Boom (IMF, 2007b), oilrelated funds have proliferated over the past decade. Of 31 oilproducing countries surveyed, 21 have established funds, 16 of which were created after 1995. 
${ }^{76}$ In some countries, funds have been set up with legal authority for own spending rather than through normal budget processes. Ghana's Mineral Development Fund, for instance, is funded with earmarked royalty revenue and expected to pay for repairs of environmental damages and development projects for mining communities. Its appropriation and disbursement arrangements are complex and not transparent. See Ghana Fiscal ROSC, 2004, paragraph 76.

${ }^{77}$ The government of Libya has indicated its intention to eliminate the practice of using the oil fund for extrabudgetary spending. The rules of the Kazakhstani oil fund have recently been amended to provide better integration with the budget.

${ }^{78}$ Problems arising from oil fund spending in the cases of Nigeria and Venezuela are illustrated in Davis and others (2003, Box 11.1, p. 293). Clarity is also necessary for provisions that allow extra spending when the oil price exceeds a certain level. Apart from the point that this practice should be avoided on economic policy grounds because it is procyclical, such practices may not be implemented transparently. ${ }^{79}$ Since 2005, Azerbaijan has reported the operations of its oil fund in the annual budget presentation to parliament (although the oil fund's budget is not subject to parliamentary approval). ${ }^{80}$ Wakeman-Linn, Mathieu, and van Selm (2003, Box 13.1, pp. 354-5) note that funds in both Azerbaijan and Kazakhstan are subject to independent audits by an international accounting firm, and the audit reports, in principle, are published. In Azerbaijan, the supervisory board is appointed with a six-month rotation of the chairmanship; in Kazakhstan, the board is chaired by the country's president. ${ }^{81}$ IMF (2007b) notes that oil funds can play a useful role in asset management.
82. Operational rules for resource funds should facilitate the process of meeting basic fiscal policy objectives through the budget. Aligning resource funds with general budgetary practices will reduce the risks of creating a dual budget through direct spending from a resource-related fund or undermining the transparency or efficiency of budgetary spending by earmarking revenues for specific purposes. ${ }^{76}$ Rigid operational rules-such as a requirement that a predetermined share of specified resource revenues be deposited in the fund or that deposits or withdrawals be linked to the level of prices or revenues-can complicate, or at times conflict with, fiscal policy. ${ }^{77}$ In all cases, the law governing fund spending should clearly specify the purpose and encourage parliamentary scrutiny.

83. Key procedural rules that should apply to resource fund operations include the following:

- There should be a clear specification of operational rules and responsibilities over spending and borrowing by resource funds. ${ }^{78}$

- The fund revenues, expenses, and balance sheet should be presented to the legislature and the public together with the annual budget, including a consolidated account. ${ }^{79}$

- No money should be spent directly from such funds; any use of such funds should be through the government budget and subject to normal budget appropriation processes.

- Fund activities should be regularly reported to the legislature and the public and externally audited by an independent auditor; and reports and audit results should be published.

- An independent supervisory board should be appointed to give assurance of good governance. ${ }^{80}$

\section{Fiscal Policy and Asset Management}

2.1.2/1.2.5

The investment policies for assets accumulated through resource revenue savings should be clearly stated, including through a statement in the annual budget documents.

84. For resource-rich countries that are accumulating financial assets from savings of resource revenue, establishing a sound asset management strategy becomes an important element of fiscal policy. The strategy should reflect ultimate objectives, such as the relative importance of savings and stabilization, and macroeconomic considerations, such as the desire to avoid exchange rate appreciation. ${ }^{81}$ Clear investment guidelines that are available to the public should govern the separate asset management function, and fund managers should be accountable for investment performance. The guidelines should provide clear direction on risks versus returns, types of assets allowed for investment, and geographical and currency composition of assets. Asset management formulation should be in the hands of the finance ministry to ensure coordination with overall fiscal policies; and changes to asset management 


\section{Box 4. Norway's Pension Fund-Global: Best Practice Asset Management}

Norway has a well-formulated and transparent asset management strategy for its Government Pension Fund-Global. The Ministry of Finance bears overall responsibility for the fund's asset management, but has delegated the task of the operational asset management to the central bank (Norges Bank) based on a management agreement. The Ministry of Finance defines the strategy for investment by identifying a benchmark portfolio against which Norges Bank seeks to achieve the highest possible return. However, the Ministry of Finance also controls exposure to risk so that the actual return should remain within a range around the return on the benchmark portfolio. (See http://www.norges-bank. no/english/petroleum_fund/management/strategy.html.)

The benchmark portfolio is composed of stocks in the Financial Times Stock Exchange equity indices in 27 countries and of the bonds in the Lehman Global Aggregate bond indices in the currencies of 21 countries. Equities account for 40 percent of the benchmark portfolio as follows: 50 percent equities listed in European exchanges and 50 percent equities listed in the Americas, Africa, and Asia/Oceania. The remaining 60 percent of the portfolio consists of fixedincome instruments issued in European currencies (55 percent), American currencies (35 percent), and Asian currencies (10 percent).

Norges Bank has set up a separate wing for investment management (Norges Bank Investment Management, NBIM), which has separate business lines for the two asset classes. At the end of 2004 the NBIM relied on 19 professional investment companies to manage the equity portfolio of the fund with 44 different mandates, and the fixed-income portfolio of the fund was managed by 16 investment-managing companies with 21 mandates.

On November 19, 2004, Norway established ethical guidelines for the fund that came into effect in 2005. According to these guidelines, the ethical basis for the fund shall be promoted by the exercise of ownership (voting) rights to promote good corporate governance as well as negative screening and exclusion of companies from fund investment options. The guidelines can be found at http://www.regjeringen.no/en/ministries/fin/Selected-topics/The-GovernmentPension-Fund.html?id=1441.

Annual and quarterly reports are published in a timely fashion, including on the central bank's website (http://www.norges-bank.no/default_106.aspx). These reports provide detailed information about recent changes in the management of the fund, transfers to and from the budget, market trends, returns on investments and income, trends regarding risk exposure, and administrative costs. In addition, the central bank regularly issues press releases, summarizing the fund's quarterly financial performance. The fund is audited by the Office of the Auditor General based on the work performed by Norges Bank's Auditing Department.

policies should be clearly and publicly stated. The operational management could be delegated to the central bank or tendered to professional investment companies. Norway again provides a best practice example in asset management of an oil fund (Box 4).

85. The Norwegian example demonstrates how such best practices can be applied. In some other countries, political economy arguments have been 
${ }^{82}$ For example, Davis and others (2003, p. 308) cite the case of Kuwait, where the Kuwait Reserve Fund for Future Generations, which operates according to wellestablished criteria and is subject to oversight by a board of directors and parliament, prohibits the provision of information to the public on its assets, in part to insulate it from spending pressure.

${ }^{83} \mathrm{Also}$, accounts should be prepared on a gross basis. The Manual provides further details on good accounting practices. used to limit public access to information on resource-related asset holdings. ${ }^{82}$ Such prohibitions are likely to limit transparency and governance. However, even where applied, they should not preclude giving adequate assurance to the public regarding overall asset performance, including comparisons of actual performance against pre-identified benchmarks.

\section{E. Accounting for Resource Revenues}

2.2.1

The government accounting system or special fund arrangements should clearly identify all government resource revenue receipts and enable issuance of timely, comprehensive, and regular reports to the public, ideally as part of a comprehensive budget execution report. The reports should be based on a clear statement of the accounting basis (cash or accrual) and policies.

86. Resource revenues should be accounted for under the same system and rules as other revenue and expenditure, with the accounting system based on a well-established internal control system. Best practice is provided by an accounting system that allows accounting and reporting on both an accrual and a cash basis. ${ }^{83}$ This requirement is not easy to implement, considering that various types of resource revenues (e.g., signature bonuses, royalties, profit shares, corporate profit tax payments, indirect tax revenue) and recipient institutions (e.g., resource ministry, NRC, tax administration) may be involved. As a result, there may be a need for specific verification and reconciliation mechanisms and institutions.

87. In resource sectors such as oil, however, it may not be sufficient to use the existing accounting and internal control framework. It may be necessary to establish specific verification and reconciliation mechanisms and institutions to improve transparency in the flows of resource-related revenue. For example, as discussed in Chapter III, the EITI encourages governments and companies to use reporting templates that would ensure consistency and transparency in resource revenue flows between companies and host governments. 


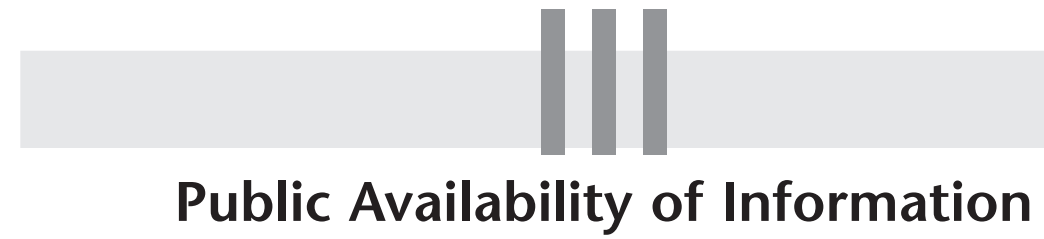

88. The public availability of information on all resource-related transactions is central to fiscal transparency. Failure in this respect has been a continuing source of concern and has given rise to a number of international initiatives aimed at promoting greater public availability of these data. The EITI is a significant new initiative that promotes, on a voluntary basis, the publication of company payments to the government as well as resource revenue receipts by the government. Beyond current revenue transactions, however, it is important that the government reports adequately on spending of such receipts, on any debt or contingent liabilities contracted against resource collateral, on its resource reserves, and on QFAs incurred in association with resource developments. ${ }^{84}$

\section{A. Budget Documentation of Resource Revenues and Spending}

3.1.1/3.1.4

All resource revenue-related transactions, including through resource funds, should be clearly identified, described, and reported in the budget process and final accounts documents.

89. Governments may receive resource revenues through a variety of tax or equivalent instruments. Budget documentation should clearly classify resource revenue-related receipts under the appropriate instrument. In some cases, some or all of those receipts may be directly placed in a resource fund. In other cases, such as the Norwegian Pension Fund-Global, all petroleum revenues and expenditures are recorded in the budget, and net proceeds are transferred to the fund. Thereafter, the necessary funds to finance the non-oil budget deficit are transferred back from the fund to the budget. ${ }^{85}$ In other countries, such as the United Kingdom, the government receives all payments directly through the revenue authorities, and these are recorded against each type of revenue instrument. In the aggregate budget documents, such receipts are not separately identified, but detailed reports on such resource revenues by type of tax or other levy are regularly produced (in the case of the United Kingdom, by

\footnotetext{
${ }^{84}$ General considerations defined in the Code and the Manual would also apply to reporting of tax expenditures benefiting the resource sector, but as discussed in Chapter I, these should be estimated against a baseline of the fiscal regime applicable to the resource sector-and defining that regime clearly is the highest priority for improving transparency in many countries.

${ }^{85}$ See http://www.statsbudsjett.no.
} 
${ }^{86}$ See http://www.inlandrevenue. gov.uk/stats/corporate_tax/ table11-11.pdf.

${ }^{87}$ Nigeria includes considerable amounts of data on oil and gas revenue flows in the budget presentation. The authorities now also publish monthly reports on oil revenue accrued to the federal government and the states (see http://www.fmf.gov.ng/ Presentaion $\% 20$ on $\% 20$ the $\% 20$ appropriation \%20bill.PDF). ${ }^{88}$ The Report of the International Advisory Group to the EITI (EITI, 2006) set out principles for determining reporting procedures for oil and gas and for mining, and the associated validation process for compliance with EITI processes, which were subsequently adopted at the EITI Oslo Conference in October 2006 (see http://www.eitransparency.org). These developments drew on the Statement of Outcomes of the March 15, 2005, EITI London Conference, which listed six minimum criteria for effective EITI implementation.
National Statistics $\left.{ }^{86}\right)$. A basic principle in each case is that the tax payments are under the supervision of the relevant tax authorities, and all transactions are included in the budget (or related) analytical presentations. In advanced countries, well-established government tax administration and reporting and auditing procedures give credibility to reported data. Some developing countries also publish basic data on oil revenues in their budget documents. However, systematic monitoring and verification of data are often inadequate. ${ }^{87}$

\section{B. Reporting on Company Resource Revenue Payments}

Reports on government receipts of company resource revenue payments should be made publicly available as part of the government budget and accounting process.

90. Many countries rely on established government accounting and reporting procedures to provide reliable information to the public on resource revenue receipts-as well as spending. In principle, governments in all countries should move toward compliance with the relevant reporting standards defined in the Code, the Manual, and this Guide, as well as the OECD Principles of Corporate Governance with reference to NRCs. However, many developing countries lack the capacity to move rapidly toward such standards. The EITI has initiated a model of standard reporting procedures to be agreed upon by a multistakeholder group in each reporting country that will help ensure that revenue receipts from natural resources are fully accounted for. ${ }^{88}$ This initiative is aimed particularly at resource-rich developing countries where general revenue and budget administration controls do not currently reach good practice levels. For such countries, compliance with the principles for establishing reporting procedures set under the EITI for governments and extraction companies should represent a substantial step forward. Governments should also lift any confidentiality provisions that would impede reporting of resource revenue payments. It is important, in this context, to emphasize that there must also be adequate assurance of data quality, as discussed further in Chapter IV.

91. Under EITI provisions, the basic standards and procedures for companies and governments to follow in reporting resource production and revenue flows are as follows:

- Regular reporting by host governments in line with a government reporting template agreed to by a multistakeholder group;

- Regular reporting by companies, including NRCs, in line with a company reporting template agreed to by a multistakeholder group;

- Wide dissemination of comprehensive and comprehensible material on payments and revenues;

- Validation and publication of reports of aggregated data, and reconciliation and analysis, by an independent third party; and

- Active participation by civil society. 
92. The EITI reporting requirements are applied only to upstream activities (that is, all activities up to the first point of marketable production-wellhead or mine gate) and are designed only for extractive industries, such as metal ores, gemstones, crude oil, and natural gas. Reporting covers a set of benefit streams defined by the multistockholder group, which may not include QFAs. To accommodate government accounting practices, and to promote reconciliation among the parties to EITI reporting, all benefit streams are reported on a consolidated cash basis.

93. Although the EITI criteria and reporting requirements cover only a narrow range of resource-related fiscal activity, they provide an important framework around which governments and companies can build a credible reporting base. Establishing a government commitment at this level and agreeing with companies on compliance with EITI reporting requirements is an important first step toward the broader goal of transparent resource revenue management. 89

94. Significant efforts are required, however, to apply the EITI mechanisms. By end-2006, some two dozen countries had either made formal commitments to participate in the EITI or indicated their intention to do so, but some had not moved beyond an expression of interest. In the future, a validation mechanism approved at the 2006 EITI Conference in Oslo will be used to determine which countries can be formally designated as EITI candidate countries (those who provide evidence of meeting four basic indicators of commitment), and which of these countries qualify as EITI compliant countries, having fully implemented EITI by meeting a series of indicators, including the publication and distribution of a validated EITI report reconciling aggregated resource-related payments reported by companies with resource-related receipts reported by the government.

95. Four phases of implementation are identified in the EITI process. The first or sign up phase determines whether a country is to be designated as an EITI candidate country and requires that four indicators be met: an undertaking to work with civil society, appointment of a senior official responsible for EITI, and publication of a costed work plan. The second or preparation phase of the EITI requires, among other things, that government remove obstacles to EITI implementation, agree on reporting templates, ensure all companies will report, and ensure that both company reports and government reports are based on audited accounts to international standards. The third or disclosure phase requirements include submission of an EITI report to the validator (the independent organization contracted to confirm that the process has been properly conducted) showing all material oil, gas, and mining payments by companies to government, and all material oil, gas, and mining revenues received by government. The fourth or dissemination phase requires that the EITI report be made available in a way that is "publicly accessible, comprehensive, and comprehensible." Any discrepancies would be highlighted and appropriate follow-up action encouraged. ${ }^{90}$

96. A number of countries have taken steps toward full implementation of the EITI in advance of establishing the validation process. Ghana and Guinea produced early reports on mining revenue collection and reconcilation. Nigeria and Azerbaijan were pilot countries for testing and evaluating the verification
${ }^{89} \mathrm{EITI}$ is not the only way to provide adequate assurance of resource revenue transparency. In the case of the Chilean mining industry, legislation ensures that economic, financial, tax, social, and environmental information from public companies is fully disclosed to the public in annual and quarterly public finance reports. Private companies, both domestic- and foreign-owned, account for about 67 percent of mining production in Chile. The main companies, through their association with the Mining Council of Chile, voluntarily and independently publish their financial statements. Individual company tax information is confidential, but aggregate information on mining tax receipts is available from the public accounts.

${ }^{90}$ See http:/ / www.eitransparency. org/about.htm for details. 
${ }^{91}$ See, for example, Ghana Fiscal ROSC, 2004, and Gabon Fiscal ROSC, 2006.

${ }^{92}$ Box 6 discusses the huge difficulties of estimating resource wealth, given the uncertainties prevailing in most extractive industry markets.

${ }^{93} \mathrm{See}$, for example, the analyses in recent IMF staff papers for Gabon (IMF Country Reports

Nos. 06/232 and 06/238), Equatorial Guinea (IMF Country Reports Nos. 06/233 and 06/237), and Nigeria (IMF Country Report No. 07/20). ${ }^{94}$ See Katz and others (2004) for a more detailed discussion.

${ }^{95} \mathrm{To}$ avoid misinterpretations owing to the effect of oil price and exchange rate changes on overall GDP, it would be useful to consider non-oil fiscal balances relative to non-oil GDP. Also, interest earnings and capital gains on assets originating from resource revenues should be excluded from the calculation of nonresource fiscal balances. However, to gauge the macroeconomic impact of fiscal policies it is also important to consider other indicators, such as the overall government budget balance or, in some cases, the public sector balance. Note that there may also be specific circumstances in which the nonresource balance may not adequately reflect the demand impact of fiscal policy actions. For example, a hike in resource taxes and their full saving is contractionary but would have little impact on the nonresource balance. Similarly, spending of resource revenues that would remove infrastructure bottlenecks or lead to the discovery of new natural resources would cause a deterioration in the nonresource balance while exaggerating its stimulus impact. process and are now producing regular EITI reports. Cameroon, Gabon, the Kyrgyz Republic, and Mauritania have also produced EITI reports. ${ }^{91}$

\section{Fiscal Balance}

The (primary) nonresource fiscal balance should be presented in budget documents as an indicator of the macroeconomic impact and sustainability of fiscal policy, in addition to the overall balance and other relevant fiscal indicators.

97. A central issue for countries rich in nonrenewable resources is how best to use revenue derived from the resource to promote a diversified economy and share the benefits with future generations. One approach is to treat resource riches as wealth, and only to consume the part of current revenue that is consistent with permanent income expectations (Barnett and Ossowski, 2003). To achieve such an objective, and therefore maintain a constant overall level of wealth (whether in untapped resources or financial assets) the nonresource primary fiscal deficit would need to be set equal to an estimate of permanent income from the government's wealth (although this estimate may of course need to be adjusted periodically because of the difficulty of assessing the value of natural resource assets).${ }^{92}$ In practice, the government might allow the actual level of the nonresource primary deficit to deviate for a period from the estimate of permanent income for macroeconomic reasons or because it decides to draw on some of its resource or financial wealth, perhaps to increase investment (human or physical). Although technically difficult, this analytical framework can play an important role in better informing the public and politicians on the policy choices that affect current and future generations and should be summarized in budget documentation. ${ }^{93}$

98. In resource-rich countries with widespread poverty, a decision to target a higher nonresource fiscal deficit for a period may in part reflect a wish to permit additional investment in schools, health clinics, and other basic infrastructure..$^{94}$ The expectation would be that the resulting increase in human and physical capital would offset the decline in resource or financial wealth. However, the actual contribution of the new investment to improved growth prospects and the timing with which any benefits are realized are difficult to predict. They will depend on a range of issues including the quality and relevance of the investment, competitiveness, market structure, and economies of scale. Moreover, consideration must be given to the macroeconomic consequences in the short term. The accumulation of financial assets to ensure medium- and long-term sustainability therefore merits explicit consideration as an integral part of fiscal policy for resource-rich countries. If these assets are invested abroad, this approach can also help mitigate problems related to real exchange rate appreciation and Dutch disease.

99. Uncertainties notwithstanding, these considerations lead to the conclusion that the primary nonresource fiscal balance is an important indicator for measuring the direction and sustainability of fiscal policy in resource-rich countries. ${ }^{95}$ Estimates should therefore be prepared from resource revenue projections of an appropriate level for this balance and used as a basis for 
determining fiscal policy and spending levels. As Barnett and Ossowski (2003, p. 51) point out with respect to oil-producing countries, however, few highlight the non-oil balance in their budgets-and it is likely that a similar observation would apply to mineral-rich countries. With respect to oil-producing countries, the IMF increasingly includes measures of the primary non-oil balance in country documents and advises country authorities to focus on such measures in budget and other fiscal policy documents.

100. Broader concepts of the fiscal balance may also be appropriate in countries where the NRC plays a large fiscal role. To the extent that NRCs have a dominant role in fiscal policy and carry out QFAs, there is a reasonable case for including them in a broad public sector balance or an indicator that consolidates with the general government all public corporations presenting fiscal risks for purposes of fiscal policy management. The general case for applying such a balance is recommended under practice 3.2.3 of the Code and described in the Manual. These considerations are particularly relevant for fiscal management in a number of resource-rich countries.

\section{Reporting on Resource-Related Debt}

3.1 .5

The government's published debt reports should identify any direct or indirect collateralization of future resource production, for instance through precommitment of production to lenders. All government contractual risks and obligations arising from such debt should be disclosed.

101. Open and timely disclosure of all contracted debt and contingent obligations is another essential element of public information. ${ }^{96} \mathrm{Such}$ a disclosure provides an added assurance of transaction flow data-deficit/surplus data should fully reconcile with accumulated debt. Full disclosure of all liabilities and contingent liabilities is essential to assessing fiscal sustainability and setting medium- and long-term fiscal policy.

102. The extensive abuse in several resource-rich countries of borrowing by collateralizing future production is documented in Global Witness (2004). As noted in Chapter I, the legal framework should carefully define proper authority to contract such loans and require public disclosure of loan terms. But this framework needs to be supported by strong requirements for reporting by both borrowers and lenders. Clear standards for reporting debt are applied in many countries and this aspect is covered in the Manual. Governance and capacity issues must be addressed in those countries that do not at present comply with basic requirements in this regard. Measures are also needed to improve disclosure by the lenders that are involved in these transactions.

\section{E. Reporting on Assets}

3.1.5

All financial assets held by government domestically or abroad, including those arising from resource-related activities, should be fully disclosed in government financial statements.

\footnotetext{
${ }^{96}$ Reporting on debt and assets (including contingencies) is a central feature of the Code and the Manual, applying to all sectors. The Government Finance Statistics Manual 2001 (IMF, 2001a) provides a framework that encourages integrated reporting of transactions, other economic flows, and assets and liabilities.
} 
${ }^{97}$ Where accrual accounts are maintained, as in the United Kingdom, these will be reported as part of the government's financial accounts (http://www. hm-treasury.gov.uk/media/ 70A0A/DebtManageRpt03to04. pdf\#page=15). The practice of reporting on financial assets even under cash basis accounting is recommended as a disclosure practice in the fiscal transparency code and by the Cash Basis International Public Sector Accounting Standard (IPSAS) issued by the International Federation of Accountants (IFAC) in January 2003.

${ }^{98} \mathrm{Few}$ industrial countries prepare estimates of natural asset wealth.

The U.S. government includes some statements in its budget documents (Analytical Perspectives) on the value of mineral rights. Stewardship assets are covered in the Financial Report of the United States Government, but mineral rights are not yet identified as an asset, in part because of concerns over the parameters for recognition of such assets in accounting statements. This difference in treatment reflects the different perspectives of budget and accounting policy, as discussed further below.
103. The standard requirements outlined in the Manual apply to questions of disclosure of government financial assets. Two specific issues arise in connection with assets related to resource revenues in developing countries. First, such assets are often held in a separate fund with disclosure requirements that may differ from those of general government. Second, in many developing countries, and indeed a number of emerging markets and some advanced countries, requirements for disclosure of financial assets are not in compliance with the Code's good practices.

104. Where assets are held in a separate fund, best practice (as in the case of Norway, see Box 4) is to set clear published guidelines for asset management and report on assets and asset management performance. Attainment of the basic elements of disclosure along these lines should be the goal of all countries-although the technical standards applied in advanced countries may not be achievable for developing countries in the near term. If assets are held simply as part of overall government assets, as is the case in the United Kingdom, reporting on financial assets becomes part of the government's overall financial reporting to the extent that reporting on financial assets has been established. ${ }^{97}$

105. Priority should be given by resource-rich countries to implementing appropriate practices for asset disclosure as soon as practicable. Tracking asset worth is a central element of a savings policy for long-term sustainability of fiscal policy. Some capacity building may be needed in this regard, but the benefits should greatly outweigh the costs.

\section{F. Estimating Resource Asset Worth}

Estimates of resource asset worth, based on probable production streams and assumptions, should be disclosed.

106. If net worth of public assets is a central fiscal policy concern, an estimate of resource asset worth is a key input. As of yet, however, countries do not systematically include clear statements of estimated value of natural resources in their budget or accounting statements, reflecting measurement difficulties, uncertainty over physical volumes and prices, and the lack of current standards even for advanced countries. ${ }^{98}$ The practice suggested above, therefore, sets a very high standard, which will be difficult to implement even for industrial countries. This Guide therefore recommends a pragmatic approach toward implementing a basic standard for low- and middle-income countries with significant new resource discoveries-essentially building on effective revenue forecasting methodology and focusing on the government's share of asset value (Box 5). An explicit calculation of resource asset worth will be an important step toward transparency, and it will provide an important basis for long-term policy. Ideally, such calculations should be published in the budget documents. The high level of uncertainty associated with such estimates, however, suggests caution in publishing quantitative estimates, given possibilities of misinterpretation. Published documents should give assurance that fiscal policy is based on 


\section{Box 5. Elements of Asset Worth Estimation for Developing Countries}

Considerable uncertainties underlie medium- to long-term revenue projections of resource revenues, particularly for countries at an early stage of development of oil or mineral resources. Technical advice to countries in these situations has largely emphasized conservative approaches to forecasting prices and revenue, ${ }^{1}$ and building a detailed analysis of field-by-field production estimates and the applicable fiscal regime, while also explaining how the baseline price assumption has been determined. Such an approach can be extended over the lifetime of mines or fields and flows discounted to present value to give a working estimate of resource wealth that can be used as a basis for fiscal policy formulation. ${ }^{2}$ Fiscal transparency principles would require that these estimates and the underlying model and assumptions be published in the policy analysis document supporting the budget. Key elements of such an approach would include the following:

- A clear statement of the principle of "asset recognition" (for instance, a conservative policy could be to include only those projects that have approved development plans and where a lease has been granted; as new developments proceed, these would be added to the economic asset inventory);

- Technical production characteristics separately specified for each field or mine (these would be government estimates that would need to be periodically calibrated against actual company production);

- Specification of the fiscal regime parameters and any exemptions applicable to each field or mine; and

- A sensitivity analysis to show likely changes in asset worth as a result of changes in key parameters, such as the baseline oil or mineral price.

${ }^{1}$ Increasingly the focus has shifted toward using realistic price forecasts (i.e., central estimates).

${ }^{2}$ This methodology is suggested as a practical starting point. In commenting on the draft Guide, however, the International Valuation Standards Committee (IVSC) noted the importance of specifying the basis for valuing asset worth and strongly recommended the use of market value or at least fair value rather than investment value. IVSC Guidance Notes 14 and 9 provide detailed instructions for the derivation and use of market inputs for such discounted cash flow estimates. (See www.ivsc.org for further details in the context of the broad work on IVS.)

sound evaluation methodology and progressively move to more detailed quantification as production becomes established.

107. In the longer term, international standards for reserve estimates could establish relevant standards for country estimates of resource asset worth. As described in Box 6, however, development of comprehensive international standards for estimating reserves poses a host of complex technical and collective action problems. Individual country action should not, however, be delayed because of the absence of a fully agreed-upon standard. On the contrary, positive action by individual countries will help provide a basis for standards of wider applicability. Moreover, the basic elements of such practices should be 


\section{Box 6. International Resource Reserves Reporting-Emerging Standards}

With respect to hydrocarbons, reports on reserves are required for listed companies, by the U.S. Securities and Exchange Commission (SEC) and by the relevant stock exchange authority in other countries. The technical definitions of reserves (promulgated by the Society of Petroleum Engineers, the World Petroleum Congresses, and the American Association of Petroleum Geologists) ${ }^{1}$ are generally accepted, but financial reporting standards still vary somewhat. The key standard for booking of oil reserves by companies is set by the SEC. The U.S. Financial Accounting Standards Board Statement No. 69, which applies to companies listed on the U.S. stock exchange, applies similar standards, placing emphasis on disclosure of proved reserves. Currently, there is no requirement for reserves disclosure to be audited. There have been frequent suggestions of a need to review these standards to take greater account of changing technology (such as allowing estimates based on seismic imaging techniques). ${ }^{2}$ A greater emphasis on third-party review of reserves estimates, for example through specialized companies, could also help enhance reliability of reserves reporting.

Very similar concerns of technical and economic uncertainty apply to estimates of mineral resources and reserves. The Australian mining industry Joint Ore Reserves Committee Code, developed in 1989 partly in response to the mining booms and busts of the 1960s in that country, has become the foundation for most recent national codes. ${ }^{3}$ The Combined Reserves International Reporting Standards Committee, initially set up in 1994, has developed a fairly standard set of definitions of resources and reserves.

The United Nations Framework Classification (UNFC) ${ }^{4}$ for energy and mineral resources has been developed as a generally applicable system harmonized with the technical standards listed above. It classifies resources in terms of three criteria: economic and commercial viability, field project status and feasibility, and geological knowledge. Reserves can then be classified in each of these dimensions by a three-digit code: 1.1.1 would signify a resource that is commercially recoverable, has been justified by a feasibility study, and is based on reasonably assured geology. In principle, the UNFC classification provides a more uniform basis for both accounting and budget statements of reserves.

${ }^{1}$ See http://www.spe.org/spe/jsp/basic/0,2396,1104_12171_0,00.html. Reserves at a particular date are defined as those quantities of petroleum that are anticipated to be commercially recovered from known accumulations. Proved reserves are limited to those quantities that are commercial under current economic conditions-and there is an expectation that they will be developed and placed on production within a reasonable time frame. Proved developed reserves are those that can be expected to be recovered through existing wells with existing equipment and operating methods. Probable and possible reserves are subject to a greater degree of technical and economic uncertainty. Proved reserve estimates are referred to as $1 \mathrm{P}$, proved plus probable as $2 \mathrm{P}$, and proved plus probable plus possible as $3 \mathrm{P}$.

${ }^{2}$ See http://www.fasb.org/st/summary/stsum69.shtml. See, however, the SEC guidance note at http://www.sec.gov/divisions/corpfin/guidance/cfactfaq.htm.

${ }^{3}$ See http://www.jorc.org/pdf/miskelly1.pdf. ${ }^{4}$ See http://www.unece.org/ie/se/reserves.html. 
applied irrespective of the level of economic development-a concern with asset worth is at least as important for developing as for advanced countries.

108. In developing such standards, an important distinction must be drawn between the use of asset worth statements for accounting or financial reports and that for budget and long-term policy purposes. Most work at the international level to date has been oriented toward the former purpose, a trend possibly driven primarily by company stock exchange listing requirements. For this purpose, although uncertainty is acknowledged, accounting reports ${ }^{99}$ are obliged to set strict (and generally conservative) criteria for asset recognition (see Box 6). ${ }^{100}$

109. Reserves estimates based on International Financial Reporting Standards (IFRS) or another national reporting standard, however, are of limited utility for purposes of setting national budget policy. Rather than determining an agreed-upon point value for resource assets to construct a balance sheet summary, long-term policymaking should be concerned primarily with potential responses to changing economic circumstances. Budget documents and other fiscal policy statements should thus clearly state the assumptions on which projections and estimates are based, and they should show the sensitivity of projections and estimates to changes in key parameters (with the resource price obviously being key, particularly in the case of oil). ${ }^{101}$ Similar technical and economic assumptions will underlie projections and estimates included in government or company financial statements and budget statements of reserves. It is essential, however, that the differing uses of these data be clearly recognized in the respective statements. More work seems required in both areas.

\section{G. Reporting Contingent Liabilities and Quasi-Fiscal Activities}

\section{1 .3}

Government contingent liabilities and the cost of resource company quasifiscal activities arising from resource-related contracts should be reported in budget accounts or other relevant documents in a form that helps assess fiscal risks and the full extent of fiscal activity.

110. Any contingent liabilities arising from resource contracts should be disclosed in budget and accounts documents. A budget annex dealing with fiscal risk (see below) could be an appropriate form of disclosure for these and other forms of contingent liability. Government guarantees should be listed in government reports on debt (but separately identified as contingent debt).

111. As described in Chapter I, energy QFAs can be very large. These QFAs deserve more analytical attention than they have received in the past, because failure to report them masks the true extent of government activity in the resource sector and the economy as a whole. As far as public expenditure QFAs are concerned, governments of low-income countries should have a particular interest in presenting social service spending to the legislature and the public as a way to demonstrate that pro-poor spending is actually higher than reported in government budgets and accounts. Companies should also
${ }^{99}$ Statistical reports also generally accept accounting criteria of asset recognition (IMF, 2001a). ${ }^{100}$ See also the 2003 version of Integrated Environmental and Economic Accounting statistical volume at http://unstats.un.org/ unsd/envAccounting/seea.htm. ${ }^{101}$ In Chile, for example, the assumption about copper prices is determined by averaging estimates produced by the members of a panel of experts. 
benefit from comprehensive and detailed disclosure of information on such spending as evidence of their corporate social responsibility. At any rate, the various mechanisms and types of QFAs outlined in Chapter I should be explained and disclosed in government budgets (e.g., as an annex to the budget) and other documents. In countries with very active NRCs and large QFAs, the fiscal reports of the government should be consolidated with that of the NRC and published.

112. Further assurance of reporting quality could be achieved if resource company reports also reported such activities clearly and in detail-particularly if these elements are subject to audit. Governments and energy companies should, as far as possible, analyze, quantitatively estimate, and regularly report the size of such activities. In the first instance, such data are likely to be most readily available through international and national company reports. Companies should be encouraged to disclose this information comprehensively and regularly through their annual reports, and they should make the basis of estimation clear and available to the government and the public. Government budget documents should derive information from these sources and regularly and systematically report on all such QFAs. These reports could be supported by analytical comments on the impact of such activities and future policies toward them.

\section{H. Fiscal Risks}

3.1 .3

Risks associated with resource revenue, particularly price risks and contingent liabilities, should be explicitly considered in annual budget documents, and measures taken to address them should be explained and their performance monitored.

113. Resource-rich countries are prone to large, sudden, and unexpected changes in output prices, especially in the case of oil. Such price changes give rise to potentially large forecasting risks for revenue and other variables, both directly and indirectly. For example, a large change in the oil price would not only affect oil revenue directly but could also trigger changes in other key variables, such as the exchange rate and interest rates, which in turn could affect expenditure and financing projections, in both the short and medium term. Annual budget documents should transparently show the baseline price assumption and how it was determined. Moreover, sensitivity analyses should be carried out to address forecasting risks, especially for the oil price assumption, and their results should be disclosed to the general public and external experts for scrutiny.

114. The Manual advises against the practice of multiple supplementary budgets within a budget year because this reduces the transparency of the budget process and shows poor budget preparation, especially if it is a chronic practice. However, this may sometimes be justifiable in resource-rich countries in the case of consecutive large shocks, providing these are properly considered in the context of their medium- and long-term impact.

115. The Manual advocates publication of a statement as part of the budget (e.g., an annex) that systematically describes risks to the fiscal position 
associated with the budget estimates of revenue, expenditure, and the deficit. For resource-rich countries, risks that should be addressed in such a statement could include guarantees on loans or commitments (explicit or implicit) for environmental cleanup operations, other contingent liabilities, the holding of inventories, unforeseen shocks to costs and output variations (for example, in the case of oil mandated through OPEC), or unclear expenditure commitments or otherwise imprecisely defined fiscal policies. ${ }^{102}$ There may be implicit as well as explicit contingent liabilities. For instance, NRCs or other state-owned enterprises involved in resource exploitation or trading may have incurred liabilities (including labor-related expenditures and contingencies) that ultimately are likely to be served by the government. Risks from unclear expenditure commitments or imprecisely defined fiscal policies could include budgetary contingency clauses that allow higher than budgeted spending if the oil price exceeds a certain trigger level. ${ }^{103}$

116. Measures to manage such risks should also be clearly explained. These measures could include provisions in government budgets or financial plans of NRCs. Governments should, at a minimum, appropriate the expected cash costs of payments on called guarantees in the next budget year. If an oil price contingency rule exists, the trigger price should be clearly established ex ante, and procedures should also be established ex ante that set possible limitations on the contingency spending and determine the budget formulation and decision processes to be used prior to authorizing any contingency spending.

117. Governments may use market-based hedging strategies to help manage their oil price risk. ${ }^{104}$ Such strategies involve locking in the price of future production now or insuring against large price falls, or both. ${ }^{105}$ In this way, rather than trying to cope with a volatile and unpredictable revenue stream, the revenue stream itself is made more stable and predictable. Hedging, however, may be constrained by political concerns, lack of implementation capacity and creditworthiness. Full transparency in implementing such strategies also presents difficulties for major exporters because of market sensitivity to such information.

118. The development of a hedging strategy and individual hedging decisions should be based on the general principle of conservatism and a clear set of rules and institutional responsibilities. For example, hedging by NRCs beyond that of short-term (1-2 months) commercial purposes and hedging by the government should be based on the same rules as far as accountability is concerned. 106 Governments that are using hedging strategies to mitigate price risk should inform the general public about the advantages (e.g., price and revenue stability, reduced risk of revenue shortfalls) as well as the costs (e.g., premiums, margin requirements) and risks (including the risks of not hedging). An explicit budget provision indicating broad estimates of these costs and benefits-but without revealing market-sensitive information-may be an appropriate method for governments to use transparently to insure against price risks over the budget year. Governments should also report ex post, publicly and regularly, any hedging activities of NRCs that go beyond short-term hedging and are not undertaken for the purpose of hedging the government budget price and revenue risk.
${ }^{102}$ Potential cleanup costs should be covered by companies, perhaps by a provision on their balance sheet, or in a separate escrow account, and be secure even if the concession is sold. Governments should provide full details of the relevant contractual arrangements and the potential fiscal exposure to cleanup costs in the event of unexpected events or defaults. A discussion of the potential costs and other issues associated with environmental cleanup operations can be found on the website of the International Council on Mining and Metals at http://www. icmm.com/library_pub_detail. php?rcd=191.

${ }^{103}$ The Islamic Republic of Iran introduced such a contingency clause in its 2000/01 budget, allowing higher spending than originally budgeted if the average crude oil price exceeded the assumed average price per barrel. ${ }^{104}$ Mexico is an example of a country that hedged oil price risk successfully in 1990 and 1991 during the Gulf War to mitigate the risk of a price drop for its 1991 budget.

${ }^{105}$ Governments (or NRCs) can hedge through either established markets (e.g., the New York Mercantile Exchange) or bilateral, tailor-made arrangements with financial intermediaries that are commonly referred to as over-the-counter market (OTM) instruments. The most liquid part of the forward market is near term (up to 18 months), which should be sufficient to hedge against the oil price risk for one budget year in advance. However, hedging large quantities would appear more difficult for longer periods ahead. See Daniel (2003) for a detailed discussion.

${ }^{106}$ Which was, for example, not the case in the oil sector in Venezuela in the early 1990s, when the government could only undertake hedging operations with parliamentary approval, whereas the national oil company could hedge without such approval (Claessens and Varangis, 1994). 
119. Hedging generally involves complex strategies and transactions, requiring a certain level of institutional capacity to ensure adequate management and administration, including recording, reporting, internal control, and evaluation and audit mechanisms to protect against speculative transactions or mistakes. Countries that do not have adequate capacity in these respects should seek support to strengthen the key institutions before engaging in hedging strategies. 


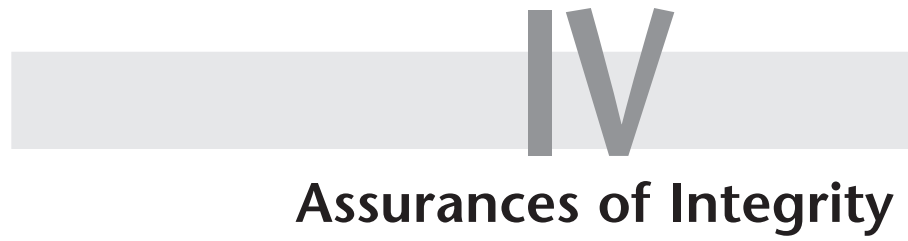

120. The need for effective mechanisms to provide assurances of integrity is especially important in the case of resource revenue flows. The magnitude of these transactions and their technical complexity provide a high exposure to risks of malpractice. In developing countries, this situation is often combined with a lack of technical capacity and political failure to address risks adequately. The inherent risks ${ }^{107}$ associated with resource sectors require that governments place special emphasis on data quality, internal controls, and independent external audit. This chapter of the Guide examines some key requirements for establishing good practice in this area of the Code. The role of the EITI validation process is highlighted again in this context.

\section{A. Internal Control and Audit of Resource Revenues}

4.2.5

Internal control and audit procedures for handling resource revenue receipts through government accounts or special fund arrangements, and any spending of such receipts through special funds, should be clearly described and disclosed to the public.

121. The special risks and complexity of resource transactions require that procedures of internal control and audit of resource revenue flows go beyond standard government rules and procedures in a number of respects. As noted above, tax administration for resource revenue flows is complex and requires specialist skills, which are generally in short supply in developing country administrations. Internal controls should be clearly defined and subject to periodic external review that is accessible to the public. In advanced countries, the national audit office can provide adequate assurance that such controls are in place. In the United Kingdom, for instance, the National Audit Office periodically reviews high-risk government processes to establish that internal controls are adequate. Its 2000 report on the petroleum revenue tax examined key areas of risk (such as misstated production volume or value, misstated claims for allowable expenditure, or nonsettlement of tax liabilities) and gave assurance that Inland Revenue is adequately managing the risks asso-
${ }^{107}$ Inherent risks and the potential for corruption in the petroleum sector are described in McPherson and MacSearraigh (2007). Inherent risk factors include volume of transactions, rents arising from its oligopolistic nature, concentration of revenue flows, complexity, and the strategic significance of the sector. 
${ }^{108}$ See http://www.nao.org.uk/ publications/nao_reports/0001/00015.pdf.

${ }^{109}$ As part of the financial audit, the Nigeria report covers control and information flow issues in government financial systems (http://www.neiti.org/ FARFinIssues\%20in\% 20Govt. pdf). It recommends a wide review of the information and management systems of the key sources of revenue (sale of equity crude by the Crude Oil Marketing Department, management of petroleum resources by the Department of Petroleum Resources, and the management of taxation).

${ }^{110}$ For example, many tax laws base provisional tax payments on the previous year's assessment. However, this is irrelevant in the start-up phase of a mining or petroleum project. The tax legal framework should include provisions allowing the tax administration to determine when the previous year's assessment should be used and when a forward estimate of income should be used. ciated with this tax. ${ }^{108}$ For developing countries, weakness in both government internal audit and the national audit office may require that an independent external source provide the necessary assurance. Nigeria, as a pilot exercise under the Nigerian EITI, has recently followed this path and engaged an independent company to carry out a comprehensive, financial, physical, and process audit of its oil and gas revenue administration. The report, completed in April 2006, is available on the Internet. It reveals significant weaknesses in revenue administration, but it represents an important step toward transparency and the establishment of effective internal controls. ${ }^{109}$

122. Standard control and audit procedures should be applied to spending of resource-related revenue (including through resource stabilization and savings funds) in the same manner as they apply to ministries and other government bodies.

\section{B. Tax Administration Openness}

4.2.6/1.2.1

Tax administration should be conducted to ensure that resource companies understand their obligations, entitlements, and rights. The scope for discretionary action by tax officials should be clearly defined in laws and regulations, and the adequacy of sector skills and standard or sector-specific procedures should be open to review.

123. General transparency considerations suggest the need for a tax administration framework that is clear and understandable and covers all procedures related to taxpayers' rights and obligations, revenue administration powers, and adequate dispute resolution processes. Within this general framework, tax administration for resource companies is often best centralized in a large taxpayer unit; specialized sectors within such a unit would usually be organized along clear functional lines and with a sector-based audit program emphasizing field audits.

124. Staff in such specialized units should be well qualified to deal with complex sector-specific issues, including, for example, transfer pricing and petroleum cost accounting, and should work closely with industry representatives to identify and resolve uncertainties in the application of relevant tax laws, which may also involve explaining the administration's views through public rulings or education programs. Although some scope for discretionary action by tax administrators is necessary given the complex environment of major resource development, ${ }^{110}$ this should be clearly defined in laws and regulations to avoid corruption initiated by companies or government on the one hand and unduly aggressive assessments of resource companies by tax officials on the other. Strengthening dispute resolution mechanisms, both at the administrative level and through the courts, is necessary to address the latter problem. Finally, tax administration staff should be able to offer professional service, advice, and assistance to help taxpayers understand their rights, obligations, and entitlements under the tax laws. Service and other standards that taxpayers can expect the administration to meet should be published. 
125. Tax information systems need to be in place and maintained centrally to allow tax officials and others (for example, under EITI) to reconcile tax office data on company resource revenue and costs with data from other sources. ${ }^{111}$ Moreover, it is important to ensure a regular flow of relevant data and information on resource revenue from other organizations to the tax office (and vice versa) to keep all relevant government offices promptly and comprehensively informed about recent developments. At the same time, the tax administration should keep information it holds about a taxpayer confidential in accordance with the law, although under certain limited circumstances the law may permit the tax administration to disclose taxpayer information to other government agencies (e.g., for law enforcement or statistical purposes).

126. The tax administration's work plans and performance indicators, including those for the specialized unit dealing with resource revenue companies, should be published ex ante, and ex post annual reports should be provided to the legislature on performance during the year. Both ex ante and ex post reports should be available to the public. Tax administration and other agencies receiving resource revenue payments also need to be made subject to the standard external auditing requirements, and these audit reports should be published.

127. The standard requirements for assurance of integrity described in the Manual apply to resource-related transactions: data should meet accepted quality criteria and there should be adequate oversight mechanisms in place. The need for adequate oversight of accounts of NRCs and other relevant companies, as well as government accounts, is of specific importance to resource-related transactions. Oversight of these transactions is particularly emphasized under the EITI.

\section{Oversight of Companies}

\subsection{1/1.1.5}

International and national resource companies should comply fully with internationally accepted standards for accounting, auditing, and publication of accounts.

128. International companies can be expected to observe the audit-related transparency and disclosure requirements under the OECD's Principles of Corporate Governance. These suggest that annual audits should be conducted by an independent, competent, and qualified auditor to provide an external and objective assurance to the board and shareholders that the financial statements fairly represent the financial position and performance of the company in all material respects. ${ }^{112}$ Also, these companies are obliged to comply with internationally accepted accounting and audit standards, including, for example, the recommendations of the Statement of Recommended Practice of the Oil Industry Accounting Committee (2001). Although these requirements are outside the scope of the Code, adherence to relevant company and auditing standards by both international and domestic private sector companies in the resource sectors is a critical element of effective resource
${ }^{111}$ Where elements of tax administration are split between the finance minister and a resource minister (for PSCs), it is particularly important that all revenue flows be accessible through a centralized information system. ${ }^{112}$ See OECD (2004, p. 22). See also the $O E C D$ Guidelines for Multinational Enterprises (OECD, 2000). 
${ }^{113}$ Note also that IFRS do not require reporting of countryspecific data. Improvement in this respect will be an important element of EITI implementation. Where NRCs have international operations, similar considerations may be relevant.

${ }^{114}$ See http://www.globalcorruptionreport.org/.

${ }_{115}$ Progress to date is reviewed at http://www.oecd.org/dataoecd/19/39/36872226.pdf.

${ }^{116}$ The Republic of Congo is a case in point. In Azerbaijan, the NRC (called SOCAR) will be required to prepare, as part of a wider financial restructuring plan, annual consolidated financial statements in accordance with IFRS starting in 2008. revenue management. Application of such standards is therefore supported by the Guide. International resource companies generally do comply with International Financial Reporting Standards (IFRS), but this is often not the case for NRCs in low- and middle-income countries. ${ }^{113}$ Therefore, one of the first requirements for NRCs is that they need to apply IFRS, including to the consolidated accounts that cover all of their subsidiaries.

129. The international dimension of company operations, however, requires coordinated action to ensure that internal and national oversight mechanisms are effective. Increasing concern with corruption in international business dealings has led to the development of national laws and international agreements to help oversee and control such practices. The U.S. Foreign Corrupt Practices Act (US Code 15, 78 dd et seq.), passed by the U.S. Congress in 1977, was the first major piece of legislation of this kind. The 1997 OECD Convention on Combating Bribery of Foreign Public Officials in International Business Transactions represents a widely supported effort (with 35 signatories) to establish similar legislation as a standard feature for developed countries. The 2004 Transparency International global corruption report, however, notes that although all of the signatories have passed laws making foreign bribery a crime, few national governments have enforced the new laws, with the United States being a notable exception. ${ }^{114}$ The OECD Working Group on Bribery monitors implementation of the convention, and, since 2001, phase II monitoring has been concerned with effectiveness of national enforcement. ${ }^{115}$

130. NRCs, as well as any domestic private sector companies involved in the resource sectors, should be made subject to standard company audit requirements, and there may also be a case for oversight by the national audit office (the government external auditor), particularly where the national audit office has a mandate and capacity to audit state-owned enterprises. There may be cases that require special audits of NRCs. Auditing of NRCs, however, is often a critical weakness, which in a number of countries has led IMF-supported programs to require that such audits be undertaken. ${ }^{116}$ In this context, the selection of independent auditing companies should be based on a transparent tendering and selection process. Audit reports should be published. Tax administration and other agencies receiving resource revenue payments also need to be made subject to the standard external auditing requirements. External audit of government agencies and state-owned enterprises is often found to be a particularly weak area of fiscal transparency in developing countries. Special efforts to improve resource revenue transparency could usefully be combined with training and technical assistance.

\section{Oversight of Company/Government Revenue Flows}

4.3.1

A national audit office or other independent organization should report regularly to the legislature on the revenue flows between international and national companies and the government, and on any discrepancies between different sets of data on these flows. 
131. It normally falls within the mandate of the national audit office to ensure the integrity of government revenue flows. The general provisions of the Code should apply equally to resource revenues. However, in many cases, the national audit office lacks the mandate or expertise to audit such revenues, particularly when a significant portion of revenues flow through NRCs/NOCs. Establishing effective internal management and control systems (following practices outlined elsewhere in this Guide) will facilitate the task of the national audit office. The traditional transactions-based audit practiced in most developed countries often fails to address the key systemic issues that are prevalent in resource-rich countries. Risk-based approaches (as illustrated by the U.K. and Nigerian examples cited above) need to be applied more widely and given full political support for the underlying problems to be addressed and credible assurance of integrity given. ${ }^{117}$

132. The validation mechanism under the EITI represents an important step toward establishing credible assurance of revenue flows, which in turn should help promote longer-term institutional change. The mechanism requires an independent validator to verify the procedures adopted to assess, compare, and report on both the aggregate payments to government reported by companies (including state-owned resource companies) and the aggregate payments received by government from companies. The validation process is not a financial audit, and it does not remove the need to establish an effective government audit process. Commercial auditors and national audit offices would continue to carry out these functions. However, the validation report can comment on the adequacy of such processes in relation to EITI validation principles. This approach is of central importance to EITI implementation. It also provides a starting point for national agencies to build their own capacity and participate effectively in the assurance process. Country development partners can help augment the capacity of national audit bodies, possibly by supporting systemic recommendations made by EITI validators.

133. Local CSOs can also play a vital role in providing independent assurance of integrity of processes and data. At a general level, the Manual advocates independent scrutiny of macroeconomic forecasts, and in some countries CSOs have taken on such a role (for instance, in Ukraine). The EITI has given much more emphasis to the potential role of CSOs in providing assurance of integrity of resource revenue data. Active participation of CSOs is seen as one of the key criteria by which effective implementation of the EITI is to be judged. One promising example of effective engagement of CSOs in promoting transparency is the Memorandum of Understanding (see http:/ / www.eitransparency.org/section/countries/_azerbaijan/_mou) signed by Azerbaijan's State Commission, aimed at guaranteeing a fundamental role for local CSOs in the design and monitoring of EITI implementation.
${ }^{117}$ See also Daniel (2002b), who emphasizes the importance of flow of funds analysis as a check that the "fiscal system delivers what it should." 

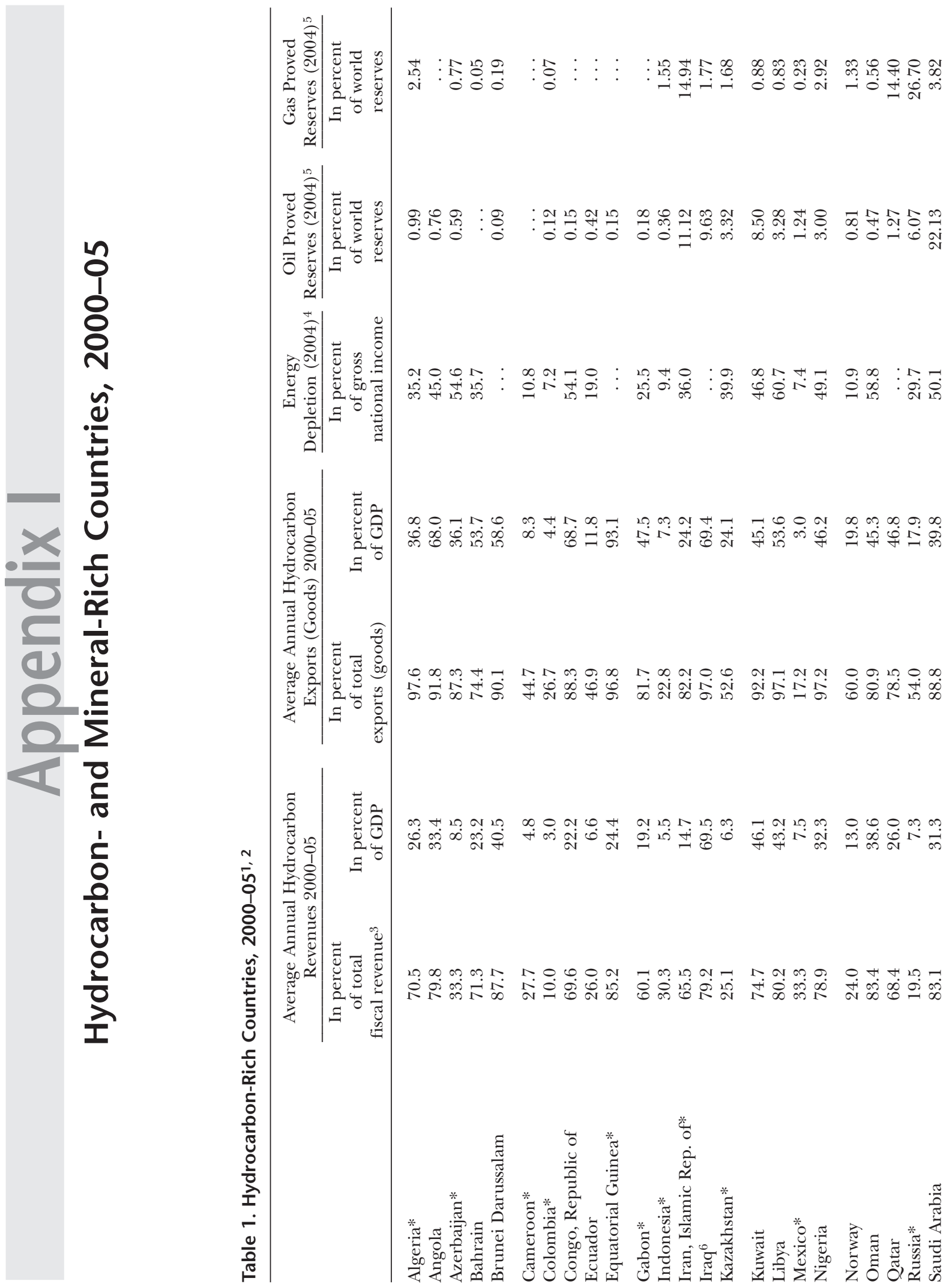


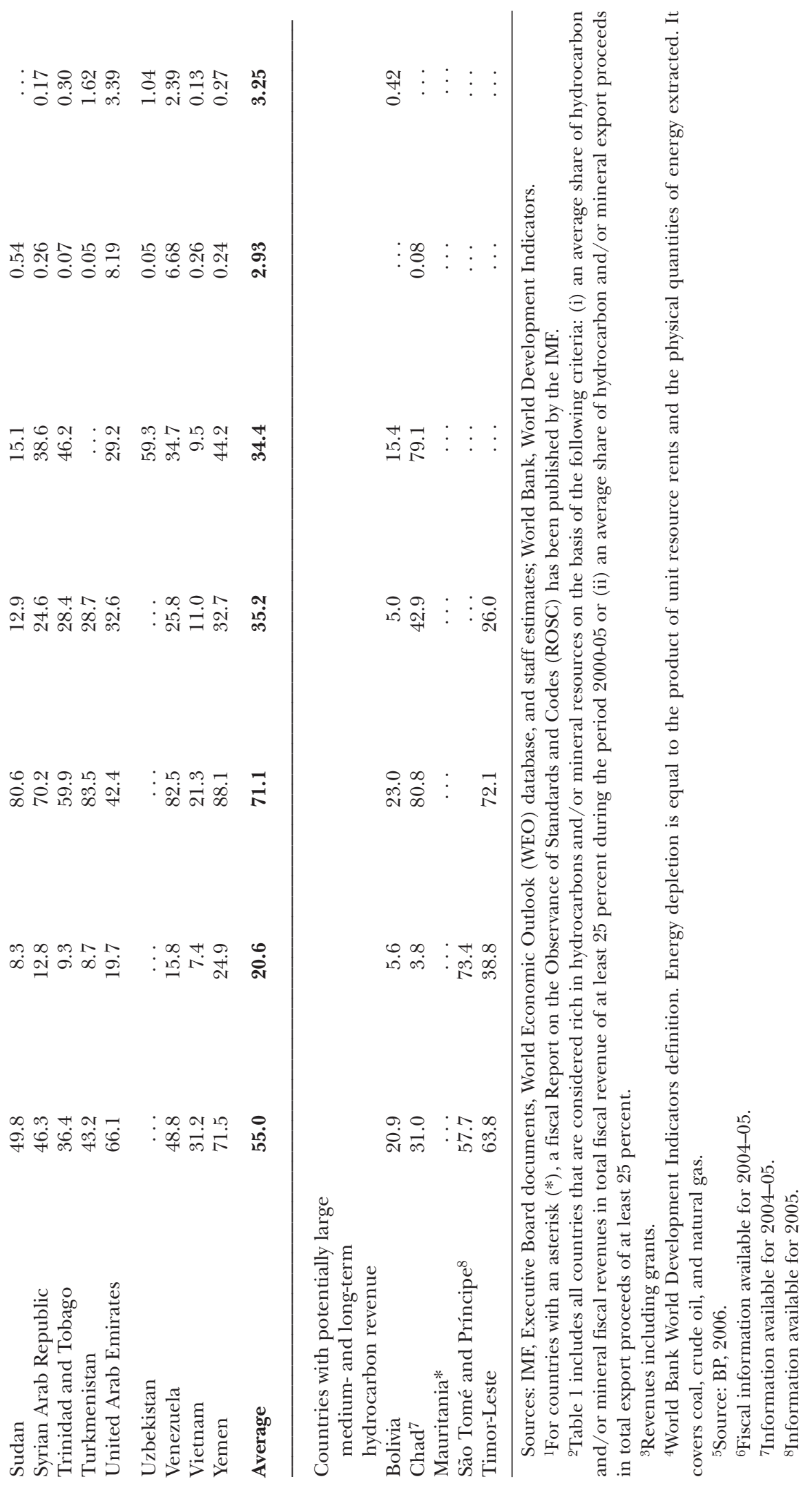




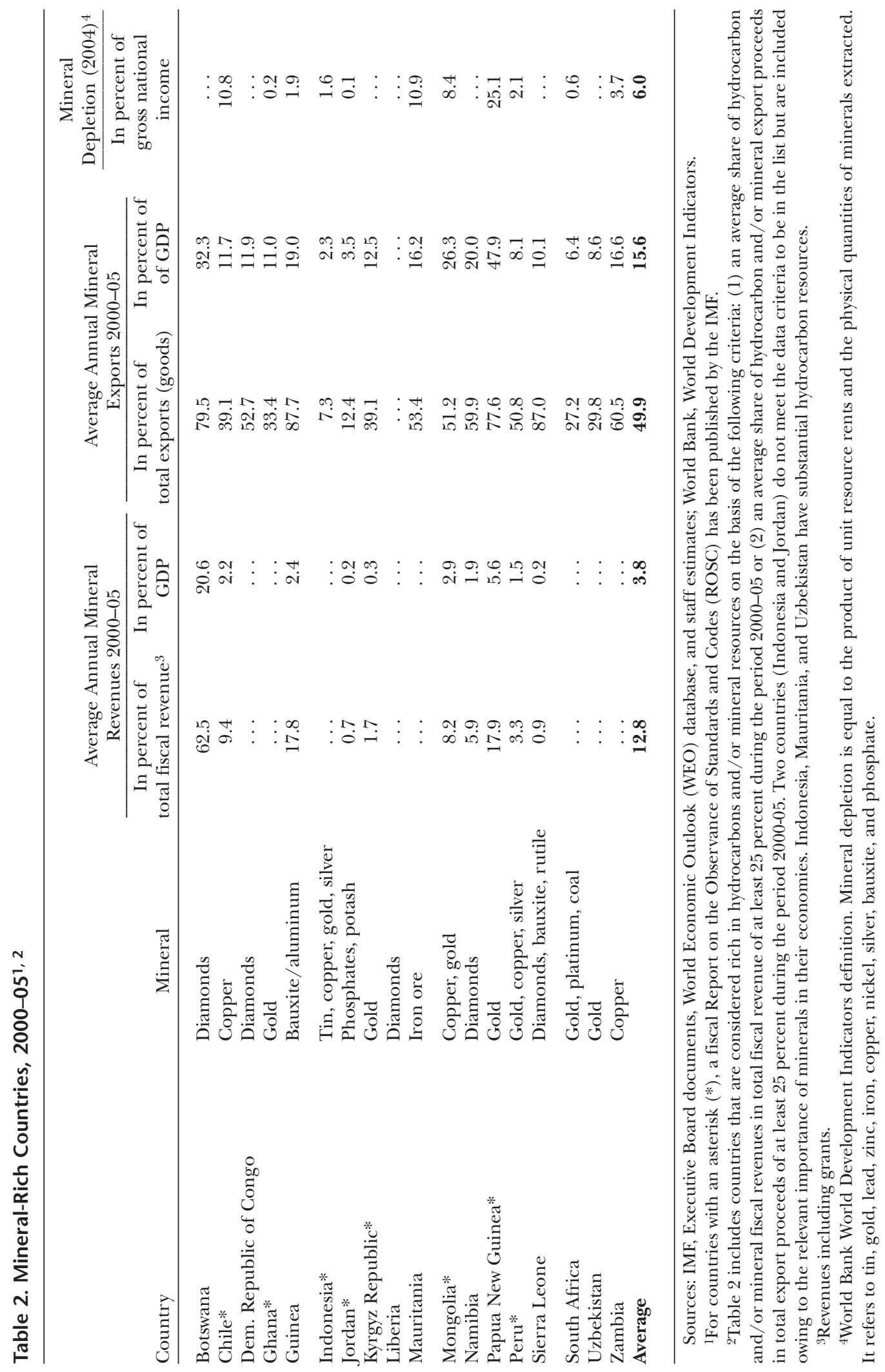




\section{Appendix II Revised Code of Good Practices on Fiscal Transparency (2007)}

\section{Clarity of Roles and Responsibilities}

1.1 The government sector should be distinguished from the rest of the public sector and from the rest of the economy, and policy and management roles within the public sector should be clear and publicly disclosed.

1.1.1 The structure and functions of government should be clear.

1.1.2 The fiscal powers of the executive, legislative, and judicial branches of government should be well defined.

1.1.3 The responsibilities of different levels of government, and the relationships between them, should be clearly specified.

1.1.4 Relationships between the government and public corporations should be based on clear arrangements.

1.1.5 Government relationships with the private sector should be conducted in an open manner, following clear rules and procedures.

1.2 There should be a clear and open legal, regulatory, and administrative framework for fiscal management.

1.2.1 The collection, commitment, and use of public funds should be governed by comprehensive budget, tax, and other public finance laws, regulations, and administrative procedures.

1.2.2 Laws and regulations related to the collection of tax and nontax revenues, and the criteria guiding administrative discretion in their application, should be accessible, clear, and understandable. Appeals of tax or non-tax obligations should be considered in a timely manner.

1.2.3 There should be sufficient time for consultation about proposed laws and regulatory changes and, where feasible, broader policy changes.

1.2.4 Contractual arrangements between the government and public or private entities, including resource companies and operators of government concessions, should be clear and publicly accessible. 
1.2.5 Government liability and asset management, including the granting of rights to use or exploit public assets, should have an explicit legal basis.

\section{Open Budget Processes}

2.1 Budget preparation should follow an established timetable and be guided by well-defined macroeconomic and fiscal policy objectives.

2.1.1 A budget calendar should be specified and adhered to. Adequate time should be allowed for the draft budget to be considered by the legislature.

2.1.2 The annual budget should be realistic, and should be prepared and presented within a comprehensive medium-term macroeconomic and fiscal policy framework. Fiscal targets and any fiscal rules should be clearly stated and explained.

2.1.3 A description of major expenditure and revenue measures, and their contribution to policy objectives, should be provided. Estimates should also be provided of their current and future budgetary impact and their broader economic implications.

2.1.4 The budget documentation should include an assessment of fiscal sustainability. The main assumptions about economic developments and policies should be realistic and clearly specified, and sensitivity analysis should be presented.

2.1.5 There should be clear mechanisms for the coordination and management of budgetary and extrabudgetary activities within the overall fiscal policy framework.

2.2 There should be clear procedures for budget execution, monitoring, and reporting.

2.2.1 The accounting system should provide a reliable basis for tracking revenues, commitments, payments, arrears, liabilities, and assets.

2.2.2 A timely midyear report on budget developments should be presented to the legislature. More frequent updates, which should be at least quarterly, should be published.

2.2.3 Supplementary revenue and expenditure proposals during the fiscal year should be presented to the legislature in a manner consistent with the original budget presentation.

2.2.4 Audited final accounts and audit reports, including reconciliation with the approved budget, should be presented to the legislature and published within a year.

\section{Public Availability of Information}

3.1 The public should be provided with comprehensive information on past, current, and projected fiscal activity and on major fiscal risks. 
3.1.1 The budget documentation, including the final accounts, and other published fiscal reports should cover all budgetary and extrabudgetary activities of the central government.

3.1.2 Information comparable to that in the annual budget should be provided for the outturns of at least the two preceding fiscal years, together with forecasts and sensitivity analysis for the main budget aggregates for at least two years following the budget.

3.1.3 Statements describing the nature and fiscal significance of central government tax expenditures, contingent liabilities, and quasi-fiscal activities should be part of the budget documentation, together with an assessment of all other major fiscal risks.

3.1.4 Receipts from all major revenue sources, including resource-related activities and foreign assistance, should be separately identified in the annual budget presentation.

3.1.5 The central government should publish information on the level and composition of its debt and financial assets, significant nondebt liabilities (including pension rights, guarantee exposure, and other contractual obligations), and natural resource assets.

3.1.6 The budget documentation should report the fiscal position of subnational governments and the finances of public corporations.

3.1.7 The government should publish a periodic report on long-term public finances.

3.2 Fiscal information should be presented in a way that facilitates policy analysis and promotes accountability.

3.2.1 A clear and simple summary guide to the budget should be widely distributed at the time of the annual budget.

3.2.2 Fiscal data should be reported on a gross basis, distinguishing revenue, expenditure, and financing, with expenditure classified by economic, functional, and administrative category.

3.2.3 The overall balance and gross debt of the general government, or their accrual equivalents, should be standard summary indicators of the government fiscal position. They should be supplemented, where appropriate, by other fiscal indicators, such as the primary balance, the public sector balance, and net debt.

3.2.4 Results achieved relative to the objectives of major budget programs should be presented to the legislature annually.

3.3 A commitment should be made to the timely publication of fiscal information.

3.3.1 The timely publication of fiscal information should be a legal obligation of government.

3.3.2 Advance release calendars for fiscal information should be announced and adhered to. 


\section{Assurances of Integrity}

4.1 Fiscal data should meet accepted data quality standards.

4.1.1 Budget forecasts and updates should reflect recent revenue and expenditure trends, underlying macroeconomic developments, and well-defined policy commitments.

4.1.2 The annual budget and final accounts should indicate the accounting basis used in the compilation and presentation of fiscal data. Generally accepted accounting standards should be followed.

4.1.3 Data in fiscal reports should be internally consistent and reconciled with relevant data from other sources. Major revisions to historical fiscal data and any changes to data classification should be explained.

4.2 Fiscal activities should be subject to effective internal oversight and safeguards.

4.2.1 Ethical standards of behavior for public servants should be clear and well publicized.

4.2.2 Public sector employment procedures and conditions should be documented and accessible to interested parties.

4.2.3 Procurement regulations, meeting international standards, should be accessible and observed in practice.

4.2.4 Purchases and sales of public assets should be undertaken in an open manner, and major transactions should be separately identified.

4.2.5 Government activities and finances should be internally audited, and audit procedures should be open to review.

4.2.6 The national revenue administration should be legally protected from political direction, ensure taxpayers' rights, and report regularly to the public on its activities.

4.3 Fiscal information should be externally scrutinized.

4.3.1 Public finances and policies should be subject to scrutiny by a national audit body or an equivalent organization that is independent of the executive.

4.3.2 The national audit body or equivalent organization should submit all reports, including its annual report, to the legislature and publish them. Mechanisms should be in place to monitor follow-up actions.

4.3.3 Independent experts should be invited to assess fiscal forecasts, the macroeconomic forecasts on which they are based, and their underlying assumptions.

4.3.4 A national statistical body should be provided with the institutional independence to verify the quality of fiscal data. 


\section{Bibliography}

Acemoglu, Daron, Simon Johnson, and James A. Robinson, 2003, "An African Success Story: Botswana," in In Search of Prosperity: Analytic Narratives on Economic Growth, ed. by Dani Rodrik (Princeton, New Jersey: Princeton University Press).

Ahmad, Ehtisham, and Giorgio Brosio, eds., 2006, Handbook of Fiscal Federalism (Cheltenham, United Kingdom: Edward Elgar Press Company).

Ahmad, Ehtisham, and Ali Mansoor, 2002, "Indonesia: Managing Decentralization," in Fiscal Decentralization, ed. by Ehtisham Ahmad and Vito Tanzi (New York: Routledge).

Ahmad, Ehtisham, and Eric Mottu, 2003, "Oil Revenue Assignments: Country Experiences and Issues," in Fiscal Policy Formulation and Implementation in OilProducing Countries, ed. by J.M. Davis, R. Ossowski, and A. Fedelino (Washington: International Monetary Fund).

Auty, Richard M., 1997, "Natural Resource Endowment, the State and Development Strategy," Journal of International Development, Vol. 9, No. 4, pp. 651-63.

Barnett, Steven, and Rolando Ossowski, 2003, "Operational Aspects of Fiscal Policy in Oil-Producing Countries," in Fiscal Policy Formulation and Implementation in OilProducing Countries, ed. by J.M. Davis, R. Ossowski, and A. Fedelino (Washington: International Monetary Fund).

Basu, Anupam, and Krishna Srinivasan, 2002, "Foreign Direct Investment in AfricaSome Case Studies," IMF Working Paper 02/61 (Washington: International Monetary Fund).

Birdsall, Nancy, and Arvind Subramanian, 2004, "Saving Iraq From Its Oil," Foreign Affairs, Vol. 83 (July/August).

British Petroleum (BP), 2006, Statistical Review of World Energy.

Brosio, Giorgio, 2003, "Oil Revenue and Fiscal Federalism," in Fiscal Policy Formulation and Implementation in Oil-Producing Countries, ed. by J.M. Davis, R. Ossowski, and A. Fedelino (Washington: International Monetary Fund).

Claessens, Stijn, and Panos Varangis, 1994, "Oil Price Instability, Hedging, and an Oil Stabilization Fund: The Case of Venezuela," Policy Research Working Paper No. 1290 (Washington: World Bank).

Collier, Paul, 1999, "On the Economic Consequences of Civil War," Oxford Economic Papers, Vol. 51 (January, pp. 168-83).

— of Civil War," paper presented at Copenhagen Consensus 2004.

Cordes, John A., 1995, "An Introduction to the Taxation of Mineral Rents," in The Taxation of Mineral Enterprises, ed. by James Otto (London: Graham \& Trotman/ Martinus Nijhoff). 
Daniel, James A., 2003, "Hedging Government Oil Price Risk," in Fiscal Policy Formulation and Implementation in Oil-Producing Countries, ed. by J.M. Davis, R. Ossowski, and A. Fedelino (Washington: International Monetary Fund).

Daniel, Philip, 1995, "Evaluating State Participation in Mineral Projects: Equity, Infrastructure and Taxation," in The Taxation of Mineral Enterprises, ed. by James Otto (London: Graham \& Trotman/Martinus Nijhoff).

— Implementation in Oil-Producing Countries at the International Monetary Fund, Washington DC, June.

_ 2002b, "Petroleum Revenue Management. An Overview," paper prepared for the World Bank, Washington DC, June.

Davis, Jeffrey, Rolando Ossowski, James A. Daniel, and Steven Barnett, 2003, "Stabilization and Savings Funds for Nonrenewable Resources: Experience and Fiscal Policy Implications," in Fiscal Policy Formulation and Implementation in OilProducing Countries, ed. by J.M. Davis, R. Ossowski, and A. Fedelino (Washington: International Monetary Fund).

Davis, Jeffrey, Rolando Ossowski, and Annalisa Fedelino, eds., 2003, Fiscal Policy Formulation and Implementation in Oil-Producing Countries (Washington: International Monetary Fund).

Extractive Industries Transparency Initiative (EITI), 2003, Revised Draft Reporting Guidelines (London, May).

—, 2005, EITI Source Book (London, March).

—, 2006, Report of the International Advisory Group (London, September).

Global Witness, 2004, Time for Transparency: Coming Clean on Oil, Mining and Gas Revenues (Washington: Global Witness Publishing Inc.).

Gupta, Sanjeev, Benedict Clements, Kevin Fletcher, and Gabriela Inchauste, 2003, "Issues in Domestic Petroleum Pricing in Oil-Producing Countries," in Fiscal Policy Formulation and Implementation in Oil-Producing Countries, ed. by J.M. Davis, R. Ossowski, and A. Fedelino (Washington: International Monetary Fund).

Hannesson, Rögnvaldur, 2001, Investing for Sustainability. The Management of Mineral Wealth (Norwell, Massachusetts: Kluwer).

Hausmann, Ricardo, and Roberto Rigobon, 2003, "An Alternative Interpretation of the 'Resource Curse' Theory and Policy Implications,” NBER Working Paper No. 9424 (Cambridge, Massachusetts: National Bureau for Economic Research).

International Monetary Fund, 2001a, Government Financial Statistics Manual 2001 (Washington).

— 2001b, Manual on Fiscal Transparency (Washington).

— 2004, Botswana: Selected Issues and Statistical Appendix, IMF Country Report No. 04/212 (Washington).

— 2007a, Manual on Fiscal Transparency (forthcoming; Washington).

_ 2007b, "The Role of Fiscal Institutions in Managing the Oil Revenue Boom." Available via the Internet at www.imf.org (Washington).

Johnston, Daniel, 2004, "Petroleum Contract Analysis and Design State-of-the ArtState-of-the-Industry," paper presented at the Petroleum Revenue Management Workshop, Joint UNDP/World Bank Energy Sector Management Assistance Program, Washington, March.

Katz, Menachem, Ulrich Bartsch, Harinder Malothra, and Milan Cuc, eds., 2004, Lifting the Oil Curse: Improving Petroleum Revenue Management in Sub-Saharan Africa (Washington: International Monetary Fund). 
Kumar, Raj, 1995, "Mine Taxation: The Evolution of Fiscal Regimes," in The Taxation of Mineral Enterprises, ed. by James Otto (London: Graham \& Trotman/Martinus Nijhoff).

Lederman, Daniel, and William F. Maloney, 2003, "Trade Structure and Growth," Policy Research Working Paper No. 3025 (Washington: World Bank).

— , 2007, Natural Resources: Neither Curse nor Destiny (Stanford, California: Stanford University Press).

Martinez-Vazquez, Jorge, and Jameson Boex, 2000, Russia's Transition to a New Federalism (Washington: World Bank).

McLure, Charles E. Jr., 2003, "The Assignment of Oil Tax Revenue," in Fiscal Policy Formulation and Implementation in Oil-Producing Countries, ed. by J.M. Davis, R. Ossowski, and A. Fedelino (Washington: International Monetary Fund).

McPherson, Charles, 2003, "National Oil Companies: Evolution, Issues, Outlook," in Fiscal Policy Formulation and Implementation in Oil-Producing Countries, ed. by J.M. Davis, R. Ossowski, and A. Fedelino (Washington: International Monetary Fund).

McPherson, Charles, and Stephen MacSearraigh, 2007, "Corruption in the Petroleum Sector," in The Many Faces of Corruption: Tracking Vulnerabilities at the Sector Level, ed. by J. Edgardo Campos and Sanjay Pradhan (Washington: World Bank).

Modise, Modise D., 2000, "Management of Mineral Revenues: The Botswana Experience," paper presented at the UNCTAD Workshop on Growth and Diversification in Mineral Economies, Cape Town, South Africa, November.

Oil Industry Accounting Committee, 2001, "Accounting for Oil and Gas Exploration, Development, Production and Decommissioning Activities," Statement of Recommended Practice (London, June).

Okogu, Bright E., 2002, "Issues in Global Natural Gas: A Primer and Analysis," Working Paper 02/40 (Washington: International Monetary Fund).

Organization for Economic Cooperation and Development (OECD), 2000, OECD Guidelines for Multinational Enterprises (Paris).

—, 2004, OECD Principles of Corporate Governance (Paris).

Otto, James, ed., 1995, The Taxation of Mineral Enterprises (London: Graham \& Trotman/ Martinus Nijhoff).

Petri, Martin, Günther Taube, and Aleh Tsyvinski, 2003, "Energy Sector Quasi-Fiscal Activities in the Countries of the Former Soviet Union," in Fiscal Policy Formulation and Implementation in Oil-Producing Countries, ed. by J.M. Davis, R. Ossowski, and A. Fedelino (Washington: International Monetary Fund).

Sachs, Jeffrey D., and Andrew M. Warner, 2000, "Natural Resource Abundance and Economic Growth," in Leading Issues in Economic Development, ed. by Gerald M. Meier and James E. Rauch (New York: Oxford University Press, 7th ed.).

Sala-i-Martin, Xavier, and Arvind Subramanian, 2003, "Addressing the Natural Resource Curse: An Illustration from Nigeria,” NBER Working Paper No. 9804 (Cambridge, Massachusettes: National Bureau of Economic Research).

Skancke, Martin, 2003, "Fiscal Policy and Petroleum Fund Management in Norway," in Fiscal Policy Formulation and Implementation in Oil-Producing Countries, ed. by J.M. Davis, R. Ossowski, and A. Fedelino (Washington: International Monetary Fund).

Sunley, Emil, Thomas Baunsgaard, and Dominique Simard, 2003, "Revenue from the Oil and Gas Sector: Issues and Country Experience," in Fiscal Policy Formulation and Implementation in Oil-Producing Countries, ed. by J.M. Davis, R. Ossowski, and A. Fedelino (Washington: International Monetary Fund).

Tanzi, Vito, 2002, "Pitfalls on the Road to Fiscal Decentralization," in Managing Fiscal Decentralization, ed. by Ehtisham Ahmad and Vito Tanzi (London: Routledge). 
Taube, Günther, 2001, "Fiscal Policy and Quasi-Fiscal Activities in the Islamic Republic of Iran," paper presented at a conference at the Central Bank of Iran, Tehran, May.

Wakeman-Linn, John, Paul Mathieu, and Bert van Selm, 2003, "Oil Funds in Transition Economies: Azerbaijan and Kazakhstan,” in Fiscal Policy Formulation and Implementation in Oil-Producing Countries, ed. by J.M. Davis, R. Ossowski, and A. Fedelino (Washington: International Monetary Fund). 


\section{Website References}

\section{Australia}

Australasian Joint Ore Reserves Committee (JORC): http://www.jorc.org/main.php

Progress on International Standards for Reporting of Mineral Resources and Reserves: http://www.jorc.org/pdf/miskellyl.pdf

\section{Democratic Republic of Congo}

Government: http://www.congo-site.com

Ministry of Finance: http://www.mefb-cg.org

\section{Nigeria}

Government of Nigeria: http:/ /www.nigeria.gov.ng/

Monthly reports on oil revenue accrued to the federal government and the states: http:/ / www.fmf.gov.ng/Presentaion \% 20on \% 20the\%20appropriation \% 20bill.PDF

\section{Norway}

Ministry of Finance (Budget): http://www.statsbudsjett.no

The Norwegian Petroleum Sector: http://www.regjeringen.no/upload/kilde/oed/ bro/2005/0004/ddd/pdfv/243848-miljo_05_engelsk.pdf

Central Bank's website: http://www.norges-bank.no/default__106.aspx

Pension Fund: http://www.regjeringen.no/en/ministries/fin/Selected-topics/TheGovernment-Pension-Fund.html?id=1441

Ministry of Petroleum and Energy: http://www.regjeringen.no/en/ministries/oed. html?id $=750$

\section{United Kingdom}

Department for International Development (DFID): http://www.dfid.gov.uk/

HM Treasury: http://www.hm-treasury.gov.uk

Debt and Reserve Management Report: http://www.hm-treasury.gov.uk/media/ 70A0A/DebtManageRpt03to04.pdf\#page $=15$

Inland Revenue: http://www.inlandrevenue.gov.uk/home.htm

http://www.nao.org.uk/publications/nao_reports/00-01/00015.pdf

National Audit Office: http://www.nao.org.uk/publications/nao_reports/00-01/ 00015.pdf

\section{United States}

Financial Accounting Standards Board: http://www.fasb.org

SEC Guidance Note: http://www.sec.gov/divisions/corpfin/guidance/cfactfaq.htm 


\section{Various}

Extractive Industries Transparency Initiative: http://www.eitransparency.org

Global Witness: http://www.globalwitness.org/

IMF Fiscal Transparency Code: http://www.imf.org/external/np/fad/trans/index.htm IMF Standards and Codes: http://www.imf.org/external/standards/index.htm

IMF Fiscal Transparency ROSCs:

Gabon: http://www.imf.org/external/pubs/ft/scr/2006/cr06388.pdf

Ghana: http://www.imf.org/external/pubs/ft/scr/2004/cr04203.pdf

Indonesia: http://www.imf.org/external/pubs/ft/scr/2006/cr06330.pdf

Joint Oil Data Initiative (JODI): http://www.jodidata.org/filez/odtmain.htm

International Council on Mining and Metals: http://www.icmm.com/library_pub_detail. php?rcd=191

Open Society Institute: http:/ /www.soros.org/

OSI Revenue Watch: Follow the Money. A Guide to Monitoring Budgets and Oil and Gas Revenue: http://www.soros.org/initiatives/cep/articles_publications/ publications/money_20041117/follow_money.pdf

Publish What You Pay: http://www.publishwhatyoupay.org

Transparency International's 2006 Corruption Perceptions Index: http://www. transparency.org/cpi

Transparency International, Global Corruption Report: http://www.globalcorruption report.org/

2003 Evian G-8 Declaration: Fighting Corruption and Improving Transparency: http:/ / www.g8.fr/evian/english/navigation/2003_g8_summit/summit_documents/ fighting_corruption_and_improving_transparency_-_a_g8_declaration.html

2006St.Petersburg G-8Declaration:FightingHigh-LevelCorruption:http:/ / en.g8russia. $\mathrm{ru} /$ docs/14.html

United Nations:

Integrated Environmental and Economic Accounting 2003: http://unstats.un. org/unsd/envAccounting/seea.htm

Economic Commission for Europe: http://www.unece.org/ie/se/reserves.html

World Bank:

Extractive Industries Review: http://web.worldbank.org/WBSITE/EXTERNAL/ TOPICS / EXTOGMC/0,, contentMDK:20605112 menuPK:592071 pagePK:148956 piPK:216618 theSitePK:336930,00.html

http:/ / siteresources.worldbank.org/INTOGMC/Resources/implementationtomr2. pdf

Petroleum Revenue Management Workshop proceedings, 2004: http://www-wds. worldbank.org/servlet/WDSContentServer/WDSP/IB/2004/08/26/000112742_ 20040826095443/Rendered/PDF/296760Petroleu1ue0ESMAP0tech0no1051.pdf 